\title{
AUSTROLIBERALISMO EN IBN JALDÚN
}

\author{
CARLOS VILLAESCUSA GARCÍA*
}

\begin{abstract}
Resumen: Las contribuciones de Ibn Jaldún al desarrollo del pensamiento económico incluidas en su gran obra al-Muqaddima han pasado casi desapercibidos en el ámbito académico occidental. En este trabajo se examinan las similitudes entre el pensamiento de Ibn Jaldún y el de los principales autores del austro-liberalismo, como Ludwig von Mises y Friedrich August von Hayek, y con el de la Escuela de Salamanca. Prestando especial atención a Jesús Huerta de Soto y su teoría de la imposibilidad del socialismo desde el punto de vista de la coacción: los efectos negativos de la interferencia del Estado en el comercio, los impuestos y contra los derechos individuales que derivan en la injusticia que causa la ruina de la civilización.

Mostramos cómo Ibn Jaldún capta la esencia de un orden espontáneo y evolutivo de las instituciones, refuta la teoría del origen divino de los reyes anticipándose a la ilustración ya desde la Edad Media. Y en definitiva, aspectos económicos importantes comunes con las corrientes austro-liberales como son: la división del trabajo o especialización, la cooperación, el papel de los mercados, el sistema de precios, el ahorro como condición para la prosperidad, la riqueza de las naciones por razones de mayor o menor población, el concepto de la curva de Laffer, una intuición de la teoría cuantitativa del dinero, compresión de la naturaleza subjetiva del valor, o la interpretación correcta de la historia.
\end{abstract}

Palabras clave: Liberalismo, intervencionismo, coacción, Escuela Salamanca, Escuela Austriaca.

Clasificación JEL: B53.

Abstract: Ibn Khaldun's contributions to the development of economic thought in his great work al-Muqaddima have received almost no attention in Western

* Programa de doctorado. Universidad Rey Juan Carlos. Dirección: Calle Alemania, 7, E: 7, P: 4. ․ F, C.P. 04740 Roquetas de Mar - Almería. Teléfonos: 950931084 y 610963 031. E-mail: carlos@fincasdealmeria.com

Procesos de Mercado: Revista Europea de Economía Política Vol. VIII, n.․ 2, Otoño 2011, pp. 13 a 81 
academia. This paper studies the similarities between the thought of Ibn Khaldun and that of the leading authors of the liberal Austrian School, including Ludwig von Mises and Friedrich August von Hayek, and The School of Salamanca. Special attention is given to Professor Jesús Huerta de Soto's work on the theory of the impossibility of socialism. This paper also examines how statist coercion and interventionism in areas such as trade, taxation and individual rights promote injustice and will lead to the eventual demise of civilization. The work of Ibn Khaldun captured the essence of a spontaneous order and of the evolution of institutions, and refuted the theory of the divine origin of kings well before the Age of Enlightenment. Lastly, this paper touches on important economic issues of interest to Austrian liberals such as the division of labor and specialization, cooperation, the role of markets, the price system, savings as a rationale for prosperity, the relation of wealth to population, the Laffer curve, the quantity theory of money, the subjective nature of value, and the correct interpretation of history.

Key words: Liberalism, interventionism, coercion, Salamanca School, Austrian School.

JEL Classification: B53.

\section{I \\ INTRODUCCIÓN}

Pocas palabras resumirían mejor la idea de este ensayo que las pronunciadas por Hayek al comienzo de su introducción al libro Principios de Economía Política de Carl Menger: «La historia de la economía política es rica en ejemplos de precursores olvidados, cuya obra no despertó ningún eco en su tiempo y que sólo fueron redescubiertos cuando sus ideas más importantes habían sido ya difundidas por otros» (Menger, 1997: 43). El objetivo del presente trabajo es demostrar que Ibn Jaldún (1332-1406) es un autor liberal y protoaustriaco. Trabajamos para ello estudiando su gran obra «Historia Universal», titulada en árabe «Libro de las Experiencias» ${ }^{1}$ (Kitab al-'ibar), acabada en 1379 y compuesta de una

1 También traducido como «Libro de los ejemplos, o de las advertencias, o de las lecciones». 
introducción y tres libros. La «Introducción», literalmente alMuqaddima, y conocida en occidente con el nombre de Prolegómenos es traducida también como Introducción a la historia universal, comprende la propia introducción y el libro primero, ambos con admirables reflexiones sobre la civilización humana que es la parte que nos ocupa en este trabajo.

Ibn Jaldún es considerado como el padre de la sociología y respetado ampliamente en el ámbito académico por los estudiosos occidentales. Sin embargo, éstos muchas veces ignoran sus aportaciones en el campo de la economía, y constatamos que esta omisión todavía es mayor si cabe desde algunas corrientes izquierdistas, que al impregnar y atraer hacia sus ideologías las ideas ajenas, las apropian y mal interpretan. Un ejemplo lo tenemos en el gran historiador inglés Arnold J. Toynbee que a pesar de su afirmación en su Estudio de la Historia de que «Ibn Jaldún concibió y formuló una filosofía de la historia que es sin duda el trabajo más grande que jamás haya sido creado por una persona en ningún tiempo y en ningún país», no creemos que entendiera ni menos atendiera las teorías económicas de corte liberal implícitas en las tesis históricas de Jaldún, pues como afirma Mises (1957: 245) «no cabe duda de que tanto Spengler como Toynbee fueron motivados por la generalizada crítica al capitalismo» y que «las doctrinas de Spengler y Toynbee muestran claramente los resultados perjudiciales que produce el olvido de la economía al tratar de los asuntos humanos». En la misma línea Huerta de Soto (1957: 71) lo sintetiza glosando a Carl Menger al afirmar «que la historia sólo puede interpretarse, ordenarse y hacerse comprensible si se tiene una teoría económica previa». Este es nuestro objetivo y metodología.

En un análisis comparativo del pensamiento de Ibn Jaldún con la perspectiva de la Escuela Austriaca de Economía, descubrimos multitud de juicios y modelos comunes como la imposibilidad del intervencionismo causante de la ruina de la civilización, la mínima intervención del estado, y otros de teoría económica y teoría evolutiva de las instituciones que, incluyendo la praxeología, merecen un estudio más profundo que continúe el trabajo aquí iniciado. El lector disculpará que este ensayo abunde en citas literales, pero qué mejor forma de transmitir el pensamiento de Ibn Jaldún que con sus propias palabras. 
Son los eminentes pensadores teóricos de la Escuela de Salamanca los precursores de la moderna concepción subjetivista del valor desarrollada por la Escuela Austriaca de Economía. Esta opinión la encontramos corroborada en Huerta de Soto (2009: 7072) donde se cita una completa lista de estudios de los historiadores económicos de mayor prestigio al respecto. Hacemos un llamamiento para la extensión de estos trabajos a los contemporáneos y predecesores islámicos de los eruditos cristianos. Un ejemplo lo ofrece Rothbard quien olvida incluir a los economistas islámicos de la época medieval, en sus estudios de dicho periodo donde tantas ideas proto-austriacas encontró. No es hasta un momento posterior, con el trabajo de los españoles del siglo XVI de la Escuela de Salamanca, cuando salen a la luz las ideas del protagonista del presente trabajo. En este sentido, también es un propósito de este estudio encontrar similitudes económicas específicas entre los escolásticos españoles y Jaldún, aunque no sus posibles influencias o vínculos.

\section{II \\ IBN JALDÚN: LIBERALISMO CONTRA INTERVENCIONISMO}

En el pensamiento de Ibn Jaldún se observa la defensa de la necesidad de una nueva economía política basada en la práctica no intervencionista con un enfoque eminentemente económico. Hizo un llamamiento para el restablecimiento de la función de la ley natural o religiosa como revisaremos en adelante, con el objetivo de garantizar el imperio de la justicia y el bienestar de la gente, en la medida en que el bienestar material y comercial del pueblo comporta la paz social. En los siguientes puntos detallamos cómo describe Jaldún que la ruina de la civilización es producto del intervencionismo económico del gobierno, que tiende inevitablemente a corromperse y a la agresión contra la libertad empresarial innata en todo ser humano y contra la propiedad privada, mediante los impuestos y demás coacciones. 


\section{La coacción como perdición de los principios de la sociedad y la civilización}

Las semejanzas de las tesis de Jaldún con el pensamiento realista de Huerta de Soto (1992), centra este análisis y, en especial, su nueva definición de socialismo como «todo sistema de agresión institucional contra el libre ejercicio de la acción humana o función empresarial», cuyo principal efecto es «impedir que actúen las fuerzas coordinadoras que hacen posible la vida en sociedad».

Huerta de Soto (1992: 150) aporta una nueva definición más precisa de socialismo, no como un sistema de agresión institucional contra una consecuencia evolutiva de la función empresarial (el derecho de propiedad), sino como un sistema de agresión contra la acción humana o función empresarial misma. Así, define el socialismo,

como todo sistema de agresión institucional al libre ejercicio de la función empresarial. Por agresión o coacción hemos de entender toda violencia física o amenaza de violencia física que se inicia o se ejerce sobre el actor por otro ser humano o grupo de seres humanos. Como consecuencia de esta coacción, la persona, que de otra forma habría ejercido libremente su función empresarial, en evitación de mayores males, se ve forzada a actuar de manera distinta a como habría actuado en otras circunstancias, modificando, por tanto, su comportamiento y adecuándolo a los fines de aquel o aquellos que le coaccionan. Podemos considerar la agresión, así definida, como la acción antihumana por excelencia. Esto es así porque la coacción impide que una persona ejerza libremente su función empresarial, (...) La agresión es, por tanto, un mal porque impide que el ser humano desarrolle la actividad que le es más propia y que por esencia y de forma más íntima le corresponde (pp. 87-88).

Huerta de Soto (1992), defiende la postura en la que el individuo goce de absoluta libertad para determinar y establecer sus fines y medios, con el único requisito de respetar las leyes o principios generales del Derecho que buscan la compatibilidad de dichos intereses propios con los intereses de los demás, fomentando la paz y la prosperidad social. 
En idéntica línea con Huerta de Soto, Vadillo (2005) cita a Ibn Jaldún con la siguiente breve sentencia:

El hombre es amo y señor de su persona congénitamente, gracias al poder que Dios le ha concedido. Si se le priva de su autoridad y se le compele a desviarse de su elevado destino de señorío, se abandona a la degradación y pierde su vigor vital, hasta el punto de perder interés por su propia procreación.

En el mismo lugar Huerta de Soto especifica que la coacción consiste en utilizar la violencia para obligar a alguien a hacer algo, y que si la coacción es sistemática y procede institucionalmente de un Estado que tiene todos los medios del poder, la posibilidad de defenderse de los mismos es muy reducida. Comparémoslo directamente con el siguiente texto original de Ibn Jaldún (6: 39) ${ }^{2}$ donde habla la imposibilidad de dirigir la sociedad mediante mandatos coactivos y que al mismo tiempo destaca y defiende los principios básicos del liberalismo como la individualidad, la libertad, la defensa de uno mismo y sus propiedades:

Así sucede a toda nación que cae en la opresión de la violencia y sobre la que se ejerce la tiranía. (...) que son tratados con violencia y coerción, esa coerción les agobia, estrecha su espíritu en su desarrollo, hace que desaparezca su interés, provoca haraganería y conduce a la mentira y al engaño. Manifiesta entonces lo que realmente no está en su espíritu, por miedo a que se alarguen sus manos contra él con saña, de manera que son la astucia y la doblez las que le enseñan, y esto se convierte en él en habito y naturaleza. Se corrompen entonces los conceptos humanos, propios de la sociedad y de la civilización, como son la defensa y la salvaguarda de uno mismo y de su casa, y se hace dependiente de los demás. Y no sólo eso, sino que el espíritu languidece y se muestra indolente para

\footnotetext{
${ }^{2}$ Las referencias a la Muqaddima o Prolegómenos a lo largo de este ensayo se mostrarán con el número de capítulo y de epígrafe entre paréntesis, separado por dos puntos. Posteriormente el número de la página al final de la cita textual de Introducción a la historia Universal, Editorial Almuzara, Córdoba 2008. Traducción de Francisco Ruiz Girela. Cuando hemos querido resaltar las palabras originales de Jaldún las hemos puesto en cursiva. El material insertado para clarificar la cita se ha puesto entre paréntesis cuadrados.
} 
adquirir las virtudes y los buenos hábitos, de manera que restringe sus capacidades y la extensión de las posibilidades humanas, y degenera y se torna en el más abyecto de los ruines (p. 1094).

La afirmación en defensa de «la salvaguardia de uno mismo, de la propiedad privada» perfila a Ibn Jaldún como un firme precursor del liberalismo, junto a la expresión «de la libertad de no tener que depender de los demás». Prosiguiendo con el análisis coactivo, Jaldún vaticina que, a la larga, la excesiva violencia, control y temor infringido por parte del poder del estado sobre la ciudadanía empujará a los hombres a dotarse como instrumento de protección de un «segundo carácter» basado en la mentira y el engaño, perdiendo la honestidad y las buenas costumbres que les son propias, conspirando contra el gobernante hasta alcanzar su desaparición (3:22, p. 326). Y a este respecto Mises (1957: 108 y 109) declara en consonancia que «el espíritu agresivo de nuestra época se origina en otra fuente: los intentos de hacer totalitario al estado y de privar al individuo de su autonomía». Y «es posible que dentro de pocos años todas las naciones hayan adoptado el sistema de planificación total y de control totalitario... El totalitarismo puede acabar con la civilización e incluso con la raza humana» (Mises, 1957: 223).

Así, las opiniones de Jaldún y Huerta de Soto (1992) coinciden plenamente en identificar a la coacción u opresión de la violencia como la más importante esencia del sistema intervencionista o socialismo: la utilización de la violencia, o violentar a alguien en contra de su voluntad para hacer algo, utilizando todo el poder del aparato del Estado. Jaldún, describiendo el régimen autoritario, narra que su poder duro, violento y vigilante, rompe el espíritu de independencia individual pues la opresión destruye los espíritus y esperanza de la gente por prosperar; un Estado así, quebranta toda integridad moral y la natural colaboración entre todos. Es una política «que atiende a lo que es conveniente al sultán y cómo mantener el poder por medio de la coerción y el uso de la fuerza. El bien común es, en este caso, secundario» (3: 50, p. 539). Huerta de Soto (1992: 87) observa la definición de socialismo más innovadora, que describe mejor la situación real actual que no es la arcaica de la propiedad estatal de los medios de 
producción; es cuando el socialismo presenta su realidad esencial con toda su crudeza: la coacción para pretender que un órgano director se encargue de las necesarias tareas de coordinar la sociedad. La responsabilidad pasa de los seres humanos de $a$ pié, protagonistas de su función empresarial - buscar los fines y crear lo que más les conviene para alcanzarlos-, a un órgano que desde arriba pretende imponer por la fuerza su particular visión del mundo o sus particulares objetivos.

Coacción y agresión institucional de Jaldún que Huerta de Soto (1992) continúa profundizando, definiendo y desmantelando científicamente como integración actual de tendencias en torno al constructivismo; o, en palabras de Hayek (1990: 34) citando a Mises, al «gobierno omnipotente», es decir, al dominio total de los aparatos políticos administrativos sobre la vida del individuo. Tanto en Huerta de Soto y, como veremos a continuación en Jaldún, la fuerza que impulsa la sociedad es nuestro espíritu o función empresarial y todo acto que frene este impulso, a través de la coacción o agresión institucional — con la imposición fiscal o la limitación del derecho de propiedad - atenta contra la coordinación y cooperación social impulsada por los empresarios, creando un desajuste sistemático que conlleva el final o la destrucción de la civilización.

\section{Consecuencias de la injusticia estatal y su manifestación contra los derechos individuales de propiedad privada y la función empresarial}

Argumentaba David Hume en sus Ensayos políticos que la grandeza de un Estado y la felicidad de sus súbditos son inseparables en relación al comercio (Hume, 1982: 4)33. Jaldún aprecia que el interés privado plasmado en el comercio o función empresarial es el principal motor del proceso del mercado y a su vez del desarrollo de la sociedad, analizado íntegramente en el epígrafe

\footnotetext{
3 Cita textual: «La grandeza de un Estado y la felicidad de sus súbditos pueden considerarse en algunos casos independientes una de otra; sin embargo, generalmente se les considera inseparables con relación al comercio.»
} 
«que trata de cómo la injusticia causa la ruina de la civilización» (3: 41), y que no es otra injusticia que la producida por la intervención del Estado:

Debe tenerse en cuenta que atacar a la gente en sus riquezas hace perder el estímulo por allegarlas y conseguirlas, porque sienten que su fin y su destino es que se las arrebaten de sus manos. Y si desaparece el estímulo por allegarlas y conseguirlas, cesa el interés por ello. Y según sea el grado de ataque a sus riquezas, en proporción a él se producirá el desinterés de los súbditos en su esfuerzo por conseguirlas. Si el ataque es intenso y amplio, y afecta a todas las formas de obtención de los medios de vida, la renuncia a obtenerlos también lo será, porque desaparece totalmente el estímulo para allegarlas de cualquier modo que sea. Y si el ataque es leve, de poca intensidad será también la renuncia a obtenerlas.

La civilización, la abundancia que genera y la actividad de los mercados sólo se logran con la actividad humana y el esfuerzo de la gente por lo que le resulta de interés ${ }^{4}$ y le proporciona ganancia, afanándose por lograrlo. Pero cuando la gente renuncia a mejorar su vida y desiste de esforzarse para conseguirlo, se paralizan los mercados y empeoran las condiciones de vida. La gente se dispersa y escapa a otras regiones para buscar el sustento en lugares que queden fuera del espacio en el que aquello se produce ${ }^{5}$. La población de esa zona se va haciendo escasa, los pueblos quedan vacíos, las ciudades se convierten en ruinas y, con su decadencia, el nivel de la dinastía y el del sultán también decaen. Porque éstos son sólo el aspecto formal de la civilización, y se deterioran inevitablemente al deteriorarse la sustancia que los conforma ${ }^{6}$... (pp. 505 y ss.)

A propósito de esto puede considerarse un fragmento de lo que narra Al-Mas Uri sobre la historia de los persas y elegido por el propio Jaldún:

${ }^{4}$ Similar a la idea original de que el interés privado o egoísta, y también la mano invisible... generan riqueza y prosperidad social.

${ }^{5}$ La coacción e intervencionismo del Estado como agresión a la propiedad privada y a la función empresarial.

${ }^{6}$ La sustancia o esencia de todo es el interés de los súbditos por la riqueza y el esfuerzo por allegarla, pero al atacarla, todo lo demás, y su forma exterior -reino, ciudades, pueblos, dinastías y sultán- se desvanece. 
« $\mathrm{O}$ h, rey!, la autoridad del soberano sólo muestra la perfección de su poder a través de la ley de Dios y del mandamiento del culto a Dios obedeciéndole y acatando sus mandamientos y prohibiciones. Pero la ley religiosa sólo puede mantenerla el rey; la autoridad del rey sólo puede ejercerse por medio de los hombres; los hombres sólo pueden mantenerse con medios materiales; los medios laborales sólo pueden obtenerse por medio de la actividad laboral; y ésta sólo puede existir si hay justicia, que es la balanza que ha sido erigida en medio de la humanidad. La erigió el Señor, y designó para que se encargase de ella a un tutor, que es el rey. Y tú joh rey!, te diriges a las fincas y se las arrebatas a sus dueños, que son quienes las habitan y están sujetos al pago del tributo sobre la tierra, que es de donde procede la riqueza. Y se las das de regalo a tus cortesanos....»

En palabras de Ibn Jaldún «lo que de esta historia debe deducirse es que la injusticia [del Rey atacando a la propiedad privada] causa la ruina de la civilización, y que esa ruina de la civilización revierte en la dinastía y provoca su decadencia y desaparición» (p. 507). Aunque aclara que el efecto no es inmediato, por ejemplo, pone el caso de grandes ciudades que sufren gradualmente decadencia, consecuencia de la acción opresora y de la injusticia que puede permanecer oculta por diversas circunstancias y debido a la abundancia de actividades que hay en la ciudad, de manera que su efecto sólo se manifiesta tras un tiempo.

Las citas relacionadas con los derechos individuales y, especialmente el de propiedad, manifiestan que no debe entenderse, como generalmente se hace, que la injusticia consiste solamente en apoderarse de los bienes o de las posesiones de sus propietarios sin compensación y sin causa justificada, sino que la injusticia cubre un espacio más amplio.

Dentro de ese ámbito Ibn Jaldún defiende el concepto de ley natural o ley religiosa, como leyes generales y abstractas que también Jaldún cataloga como evolutivas, refutando la idea del gobierno de origen divino que abordaremos en otro punto. Ahora en este extracto veremos la referencia a un orden generador de paz social basado en principios de libertad, «que trata de cómo la injusticia ocasiona la ruina de la civilización» (3:41): 
Todo aquel que se apodera de propiedad de otro o le fuerza a trabajar, o le demanda algo sin derecho, o le impone una obligación no descrita en la ley religiosa, comete una injusticia contra él. Los recaudadores de impuestos injustos, son injustos; quienes oprimen con tales impuestos, son injustos; quienes los toman por la fuerza, son injustos; quienes privan a la gente de sus derechos, son injustos; quienes de una forma o de otra se apoderan de las propiedades de los demás, son injustos. Y el mal de todo esto revierte en la dinastía causando la ruina de la civilización, que es su sustancia, al acabar con las esperanzas de la gente (p. 508).

Hume (1982: 153-163) afirmaba que era imposible que se sustentase una sociedad sin justicia, y que en el tema de los impuestos las consecuencias son diametralmente opuestas a lo que sugerían las primeras apariencias. Hume lo ilustra con un ejemplo histórico:

Los historiadores observan que una de las causas principales de la decadencia del imperio romano, fue el cambio que introdujo Constantino en las finanzas implantando una capitación general en lugar de todos los diezmos y los demás derechos e impuestos que componían antiguamente las rentas del imperio. Los pueblos de todas las provincias estaban tan oprimidos por los publicanos y tan descontentos, que quedaron sumamente satisfechos de poder sacudirse un yugo tan pesado y refugiarse bajo las banderas victoriosas de los bárbaros, cuya dominación, mucho menos artificiosa y más independiente, era preferida a la tiranía refinada de los romanos (p. 160).

Continúa Jaldún considerando los objetivos para la preservación de la vida y para evitar la injusticia que acaba de denunciar:

Debe tenerse en cuenta que ésta es la intención que el Legislador ${ }^{7}$ pretende al prohibir la injusticia, es decir, lo que de ella se generaría en forma de deterioro y ruina de la civilización, que permitiría la desaparición de la especie humana. Se trata de un objetivo general y observable en la ley religiosa, incluido en los cinco objetivos

\footnotetext{
${ }^{7}$ El Profeta Mahoma.
} 
necesarios: la preservación de la religión, de la razón, del espíritu, de la procreación y de la riqueza. Y dado que la injusticia, como hemos visto, hace posible la desaparición de la especie - pues a ello es a lo que conduce la ruina de la civilización-, el peligro que implica es manifiesto y su prohibición resulta indispensable (p. 508).

Por su lado Mises (1957: 100) en su idea de justicia comenta que un sólo individuo,

no tiene que preocuparse de las consecuencias de su propia supervivencia para los demás; no necesita la justicia. Sus únicas tareas son la higiene y la defensa. Pero en la cooperación social con otros individuos, el individuo se ve obligado a abstenerse de la conducta que es incompatible con la vida en sociedad. Sólo entonces surge la distinción entre lo que es justo y lo que es injusto...

Entonces tiene que observar lo que es beneficioso para él y no afecta a los demás: «el patrón último de la justicia es la tendencia a la preservación de la cooperación social. La conducta adecuada para preservar la cooperación social es conducta justa; la conducta contraria a la preservación de la sociedad es conducta injusta» y que «la utilidad social es el único criterio de justicia y la única guía de la legislación» (p. 101).

Siguiendo y relacionado con el hilo conductor de este texto, damos paso al epígrafe siguiente sobre los impuestos y la decadencia o fin de las civilizaciones.

\section{Los impuestos y el ocaso de la sociedad}

Jaldún justifica la eliminación de los impuestos, o que sean tan bajos como sea posible, porque reconoce como una de las causas de la ruina de una civilización la imposición de cada vez mayores impuestos para costear el lujo despótico de los gobernantes, que provocan desilusión en los comerciantes y en los agricultores para emprender sus respectivas actividades. Los mayores impuestos reducen la producción y con ello la recaudación total y los gobernantes ignorándolo continúan con una concatenación o espiral 
de subidas para mantener su nivel de privilegios y comodidades que terminan con la función empresarial, el proceso productivo y el mercado, en definitiva con la sociedad.

Como veremos a continuación, Jaldún pronostica los resultados del intervencionismo en la misma línea de Mises (1949) cuando describe «los frutos del intervencionismo» practicados durante décadas por los gobiernos del Occidente capitalista:

«... han dado lugar a guerras internacionales y a contiendas civiles; han permitido a determinados grupos oprimir despiadadamente a las masas; han producido depresiones económicas y paro masivo; han consumido capitales ingentes y, en determinadas épocas, han desatado hambres pavorosas» (p. 1009).

O en palabras de Henry Hazlitt en su artículo Los impuestos desalientan la producción, leído en Huerta de Soto (2008: 228) se resume todo: «cuanto mayor sea el porcentaje de renta nacional que absorban las cargas fiscales, tanto mayor será la disuasión ejercida sobre la producción y la actividad privada» .

Respetamos la amplitud del siguiente pasaje que lo hace merecedor de ser precursor de un análisis liberal que anticipó el denominado efecto o Curva de Laffer. Jaldún defiende que los «impuestos que tienen que pagar los ciudadanos sean tan bajos como resulte posible, ya que entonces los individuos emprenden dichas actividades [empresariales] con entusiasmo». Veamos este efecto primeramente expuesto en Mises (1949: 869):

\footnotetext{
Mantener en funcionamiento el aparato coactivo del estado exige el consumo de trabajo y de bienes. Bajo un régimen liberal, tales dispendios son de escasa importancia comparados con el volumen total de las rentas personales. En cambio, como es lógico, cuanto más amplía el poder público el ámbito de su acción, tanto más se hipertrofia el presupuesto.
}

De la misma forma, Jaldún dibuja de forma clara, rotunda y categórica la destrucción de la sociedad a través de una subida paulatina de la tasa impositiva impuesta por el poder que atenta contra la propiedad privada y libertad empresarial. Observemos un ciclo o proceso de destrucción de la función empresarial 
y la sociedad en sí misma, a través de un gobierno que incurre y degenera cada vez más en un riesgo moral, en el epígrafe "Que trata de los impuestos y de la causa de su escasez y de su abundancia» (3:36):

Debe saberse que al comienzo de la dinastía los impuestos son de pequeña cuantía pero producen una recaudación total notable; y que, al final de ella, los altos impuestos personales producen una escasa recaudación total. La causa de esto es que la dinastía, cuando sigue las normas de la religión, no exige más que las obligaciones fijadas por la ley canónica: limosna general, la contribución sobre la tierra y el impuesto de capitación. Son de pequeña cuantía, porque el monto del azaque ${ }^{8}$ sobre los bienes ${ }^{9}$ es pequeño como bien se sabe; y lo mismo ocurre con el azaque sobre los granos y sobre el ganado. Y otro tanto sucede con el impuesto de capitación, la tasa sobre la tierra y con todos los tributos que marca la ley canónica, que establece unos límites que no pueden ser sobrepasados.

Mientras lo que prima es la cohesión tribal y la superioridad, se mantienen las costumbres del desierto, como ya dijimos. Costumbres beduinas que implican tolerancia, consideración, humildad y respeto a los bienes ajenos sin pretender apropiarse de ellos salvo en ocasiones excepcionales ${ }^{10}$. Esto hace que sea pequeña la cantidad requerida a cada uno y su cuota personal, que es lo que forma el montante global. Y cuando la cuota personal y lo que tiene que pagar cada uno de los súbditos es poco, éstos se dedican con celo al trabajo y lo realizan con dedicación. Los bajos impuestos hacen que se emprendan numerosas actividades y que éstas se multipliquen para asíalcanzar el bienestar. Y cuando se emprenden muchas actividades se aumenta también el número de aquellos cupos y tasas personales, y aumenta el monto total de los impuestos.

Cuando la dinastía se asienta y permanece, y sus soberanos se suceden uno tras otro, empieza a notarse en ellos la sofisticación. El sentido profundo de la vida beduina y su sencillez desaparecen, así como sus rasgos de carácter tolerante y desinteresado. Sobreviene entonces la autoridad coercitiva y el sedentarismo generador del lujo.

\footnotetext{
deras.

8 Tributo legal sobre las propiedades y sobre las producciones agrícolas y gana-

${ }^{9}$ Los constituidos por numerario en oro y plata, y objetos de valor como vestidos, alfombras, etc.

${ }^{10}$ Indica como algo inusual las confiscaciones por parte del Estado.
} 
Los miembros de las dinastías adquieren formas de afectado refinamiento, y aumentan las pretensiones y las necesidades al darse a la comodidad y al lujo. Elevan entonces las tasas y los cupos que imponen a los súbditos: labradores, campesinos y demás tributarios. Y se incrementan los impuestos individuales y las tasas en cantidad y monto, para aumentar así la recaudación. Aumentan los impuestos y las tasas de cada individuo progresivamente para aumentar de ese modo la recaudación. Se imponen tasas sobre artículos de comercio y se establecen puntos de cobro en las puertas, como más adelante diremos. Los aumentos se producen de manera continua y de acuerdo al ritmo que van aumentando las apetencias de la dinastía en lo que a lujos y a nuevas necesidades se refiere, y los gastos que a causa de ellos se originan. Y así hasta que los impuestos que afectan a los súbditos resultan onerosos y agobiantes. Pero se han convertido en una costumbre admitida, porque los incrementos se han producido poco a poco, sin que nadie se haya percatado de lo que han aumentado ni de quién los impone, sólo que se imponen a los ciudadanos como costumbre establecida.

Y llegan a aumentar hasta sobrepasar los limites tolerables y con ello desaparece el interés emprendedor de los ciudadanos al desaparecer en sus mentes la esperanza, debido a la escasez de los beneficios, cuando comparan gastos e ingresos por una parte, con frutos y beneficios, por otra. Muchas manos se abstienen de emprender cosa alguna y entonces disminuye el total de la recaudación al reducirse aquellas cuotas individuales que la componen.

Muchas veces se aumenta la cantidad a pagar por tasas personales cuando observan ${ }^{11}$ esa disminución en la recaudación, considerando que es necesario para compensarla. Y así, hasta que tasas e impuestos individuales alcanzan un límite más allá del cual no hay beneficio ni ganancia, debido a la cantidad de gastos que implica cualquier empresa, a los altos impuestos y a la nula esperanza de alcanzar los beneficios deseados. El total de la recaudación sigue disminuyendo y el monto por persona de tasa e impuestos sigue aumentando porque están convencidos de que con ello se mantendrá la cantidad total. El daño de esta situación se vuelve contra la dinastía, ya que el beneficio de las actividades mercantiles revierte en ella.

${ }^{11}$ Los mandatarios, los miembros de la dinastía reinante. 
Si esto se entiende bien, se entenderá también que el más fuerte de los incentivos para la actividad mercantil es que los impuestos que tienen que pagar los ciudadanos sean tan bajos como resulte posible, ya que entonces los individuos emprenden dichas actividades con entusiasmo, confiados en que obtendrán beneficios con ellas. Dios -alabado y ensalzado sea-domina todas las cosas. En sus manos está el dominio de todo» ${ }^{12}$ (p. 490).

En este pasaje se observa una defensa de la actividad comercial, rompiendo así con la tendencia raramente interrumpida desde la antigua Grecia hasta la historia presente, expresada en palabras de Mises (1957: 199), que no aprueba el éxito del comerciante y la industria y su riqueza, «sólo excusable si el dueño paga por ella contribuyendo a instituciones caritativas».

El interés privado es el principal motor del proceso del mercado: «cuando la cuota personal y lo que tiene que pagar cada uno de los súbditos es poco, éstos se dedican con celo al trabajo y lo realizan con dedicación. Los bajos impuestos hacen que se emprendan numerosas actividades y que éstas se multipliquen para así alcanzar el bienestar». Y sobre la idea del coste de oportunidad, - en otros pasajes destacamos sus pioneras aportaciones al subjetivismo-, los súbditos renuncian lograr obtener un beneficio casi nulo, que supone no cubrir los jornales y otros gastos ocasionados, al no invertir su dinero sino en otro lugar o reino fuera de esa gran presión impositiva, pareciendo dirigir la economía hacia el análisis de la escasez y asignación de recursos.

Historiadores y estudiosos de Jaldún, consideran que el eje de sus concepciones es el concepto de la asabiya (Nassar, 1967: 188 y ss.; Lacoste, 1971:146 y ss.; y Valencia, 1985: 183) con diversas connotaciones definida por nosotros por cohesión tribal, que interpretamos y desciframos de forma muy distinta a la corriente citada. Y es que Jaldún explica como características necesarias, inseparables e inherentes a dicha cohesión tribal, las "costumbres beduinas que implican tolerancia, consideración, humildad y respeto a los bienes ajenos»; un acto de nobleza, virtud, justicia, tolerancia o libertad y de respecto a la propiedad privada o «los

12 Corán, XXXVI, 82. 
bienes ajenos», establecida por los primeros fundadores que respeta los «tributos que marca la ley canónica, que establece unos límites que no pueden ser sobrepasados» $\mathrm{y}$ "que son de pequeña cuantía». La pérdida de estos valores conllevarán la ruina de la civilización.

En la sociedad islámica tradicional sólo se aceptan los impuestos que imponen el Corán y la Sunna del Profeta. Jaldún es conocedor de la Ley Islámica (Shariah), y es que según argumentación de Vadillo (2005), los impuestos en el Islam están prohibidos, sólo se establece un pago único, en general, del 2,5\% de la propiedad acumulada y no utilizada durante un año entero. Este pago es un pilar espiritual, como la oración, más allá de lo exclusivamente material, no es un impuesto administrable por los gobiernos de modo estatal; se recoge y distribuye en veinticuatro horas, y sus beneficiarios están ya claramente categorizados en la Ley Islámica. Luego la Ley Islámica prohíbe el Estado, al que considera un producto histórico del estructuralismo racionalista. Gobernar es cuidar y proteger pero no es administrar. Ya que el único ámbito de la economía - como administración- es la propiedad privada, y en ningún caso puede convertirse en la administración de los bienes de otras personas o de una parte significativa de ellos, la Ley Islámica prohíbe el Estado de forma parecida a las posturas anarcocapitalistas. Sin embargo, el respeto a dicha Ley no está hoy en práctica, sólo lo defienden los más puristas y tuvo lugar en tiempos del Profeta Mahoma, quien exactamente vaticinó: «Tras mí, el califato durará treinta años, y luego retornará el poder-real despótico» leído en Vadillo (2005) y también citado en Jaldún (4: 16, p. 667).

La idea básica del anterior fragmento es que, atendiendo a la cohesión tribal - fuerza vital del pueblo o asabiya-, se deben respetar los principales valores en que la misma descansa: propiedad privada e impuestos bajos, tolerancia, solidaridad y justicia de los fundadores de las primeras comunidades. Y esta cohesión social se elimina dando paso a un mayor estatismo que incrementa los impuestos para el enriquecimiento del poder político que busca confort y que se apoltrona preocupado únicamente por su bienestar, rompiendo con las bases de la asabiya, todo lo cual conlleva a la destrucción de las civilizaciones por el abandono de 
sus habitantes ante la imposibilidad de comerciar en su suelo y obtener con ello unos beneficios mínimos dada la insostenible presión fiscal recaudatoria del Estado. ${ }^{13}$ Luego Estado y civilizaciones son antagónicos. El Estado es impensable dentro de una cohesión social que hunde sus raíces en la virtud, la nobleza, la justicia social, la tolerancia, la propiedad privada y el comercio. La asabiya es la fuerza social o motor de la sociedad y las civilizaciones; cuando se da paso al Estado, éste a través de la coerción y de los altos impuestos, inevitablemente será la causa de la perdición de su fuerza, sus valores y actividad, conllevando el fin de la sociedad.

Por todo ello, los impuestos son considerados como ilegales por la mayoría de los juristas fieles a la Shariah. En las palabras que siguen, Jaldún simboliza, con la ayuda de un sentido del humor irónico, la invalidez o desaprobación de los impuestos poniendo como ejemplo un artículo que es poco consumido en tierras islámicas, el vino. Recogida a su vez de una historia su gran maestro andalusí, Jaldún (5:11) narra:

En relación con esto escuché una historia divertida de cierto sayh de al-Magrib. Me contó mi maestro Abu Abd Allah al-Abili lo siguiente: «Estaba yo donde el cadí de Fez, en tiempos del sultán Abu Sa id. Se trataba del alfaquí Abu l-Hasan al-Malili, y se le ofreció que eligiese como sueldo alguno de los diversos tributos». Siguió diciendo: «Bajó la cabeza pensativo durante un buen rato y les dijo: La tasa sobre el vino. Los compañeros que se encontraban presentes se echaron a reír sorprendidos y le preguntaron la razón de eso, y él les dijo: Puesto que todos los impuestos son algo prohibido, he elegido aquel que los espíritus no rechazan pagar, que es el vino. Pues raramente hay alguien que dé a cambio de él su dinero sin que se sienta feliz y contento con lo que le provoca, y no le duele el haberlo dado ni sigue sintiendo apego por él». Se trata de una curiosa observación, pero Dios es más sabio (p. 718).

13 Esta situación se ve reflejada en la actualidad en la que la crisis económica provocada por el estatismo se plantea solucionar con más estatismo. Curiosamente, la mayoría de historiadores de sectores izquierdistas se preocupan de dejar claro que el pensamiento de Jaldún debe ser aplicable sólo al pasado de África del Norte. 


\section{El efecto destructor del comercio ejercido por el Estado}

Jaldún, trata como un atentado a la propiedad, a la libertad individual y como una violación de un derecho natural la participación del Rey o Estado como un actor más en el mundo de la economía a la cual distorsiona, en el epígrafe (3:38) «que trata de cómo el comercio ejercido por el sultán es un perjuicio para los súbditos y un desastre para la recaudación", y en el que ilustra los resultados de una situación dominante en el mercado del Estado respecto del sector privado o de los ciudadanos contra los que compite. Al mismo tiempo, y ligado al anterior análisis que refleja el propio efecto destructor de la civilización denunciado en Huerta de Soto (1992) — por la agresión institucional a la función empresarial y que causa el desajuste social respectivo en términos de imposibilidad del intervencionismo y la coacción-, también especifica cómo el comercio ejercido por la autoridad, estado, o sultán es un perjuicio para los ciudadanos y un desastre para la recaudación al reducirse los beneficios, y es la base de una injusticia. Fijémonos cómo aboga Jaldún por la libertad general de comprar y vender como medio de asegurar el buen funcionamiento del mercado para procurar, por un lado, al vendedor un precio suficiente para animar la producción y, por otro, al consumidor la mejor mercancía al precio más bajo - el punto de precios máximos lo comentaremos de forma diferenciada en otro pasaje - y acusa cómo todo se menoscaba con la participación del Sultán en la economía forzosamente rompiendo dicha esencia o libertad de compraventa. De ello Jaldún (3: 38) disiente, y aclara qué ocurre cuando,

(...) el propio sultán emprende actividades comerciales o agrícolas para así incrementar la recaudación, cuando ve que los comerciantes y agricultores consiguen beneficios y cosechas con los que aumentan sus riquezas, y que las ganancias son proporcionales a los capitales invertidos. Comienzan a adquirir animales y terrenos para explotarlos, y compran mercancías de manera que afecta a la situación de los mercados. Piensan que con ello harán crecer la recaudación y aumentarán los beneficios, pero es un enorme error que crea un enorme perjuicio a los súbditos de muchas maneras. En primer lugar por la dificultad de agricultores y comerciantes para 
vender sus animales y sus productos, y para obtener con facilidad lo que necesitan para su actividad. Los súbditos poseen más o menos la misma riqueza, y la competencia entre ellos ya alcanza casi el límite de sus posibilidades. Pero si el sultán compite con ellos, poseyendo como posee una fortuna mucho mayor, casi ninguno de ellos logra alcanzar nada de lo que necesita y ello hace que entren en sus almas la aflicción y el desánimo. Además, el sultán puede obtener muchas de estas cosas, cuando las necesita, bien tomándolas a la fuerza a un precio muy bajo, porque no hay nadie que se atreva a pujar con él en la compra, y puede forzar al vendedor a que baje el precio. Además, cuando los productos agrícolas y todo aquello que se recolecta o cosecha como el grano, seda, miel, azúcar y otros productos de este tipo son recogidos, y lo mismo ocurre con las mercancías objeto de comercio, no puede esperar a que los mercados fijen los precios y así obtener el producto de las ventas, porque tiene que atender a las exigencias de la dinastía. Fuerza a quienes se dedican a estos oficios, comerciantes y agricultores, a que le compren aquellas mercancías sin admitir rebaja alguna en el precio y aún lo sube. Con ello se apodera de todo su numerario, mientras que los mencionados productos quedan en manos de ellos, almacenados y sin posibilidad de salida. Se hallan entonces sin recursos, desarmados y sin posibilidad de llevar a cabo aquello de lo que obtienen sus ingresos y constituye su medio de vida. Y ocurre con frecuencia que tienen necesidad de conseguir algo de dinero en metálico y se ven obligados a vender aquellas mercancías cuando el mercado está en su peor momento y los precios más bajos. Y suele suceder que esto se repite con un comerciante o un agricultor, y hace que pierda su capital y le imposibilita seguir en el mercado. Cuando esto se repite y ocurre con frecuencia, hace que las pérdidas y los apuros económicos y la disminución de los beneficios afecten a los súbditos, y eso provoca que desaparezca totalmente el estímulo por esforzarse en esa actividad. Esto lleva a una disminución de la recaudación, y como la mayor parte de ésta proviene de los agricultores y de los comerciantes - sobre todo después de que hayan sido instituidos los aranceles comerciales y de que el monto de la recaudación haya aumentado con ellos-, si ocurre que los agricultores abandonan la agricultura y los comerciantes dejan de dedicarse al comercio, la recaudación desaparece totalmente o se ve afectada por un terrible descenso.

(...) Pues los súbditos cuando dejan de obtener fruto de sus riquezas con la agricultura y con el comercio, estas actividades 
decaen y acaban desapareciendo al no haber que gastar. Y con ello sobreviene el colapso de la situación. Entiéndase esto bien. (...) (pp. 494-497).

Se evidencia de esta reflexión su paralelismo con el pensamiento de Molinari (1849) para el que la libre competencia en el mercado no puede ser interrumpida sin que la sociedad sufra, y que esta usurpación — que un bien sea arbitrariamente caro-, se ampara necesariamente en la fuerza y coacción del Sultán sobre el comprador por ser más débil. También Mises, en La acción humana, y Temin (2009: 30), en Procesos de Mercado, encuentran las causas de la decadencia de la civilización clásica en la intervención del gobierno en los precios del mercado y la economía. «Toda injerencia estatal en la esfera mercantil repercute indirectamente sobre el consumo. Puesto que altera el mecanismo del mercado, influye forzosamente en la conducta y estimaciones valorativas de los consumidores» (Mises, 1949:863), y continúa:

La maravillosa civilización de la antigüedad desapareció porque fue incapaz de amoldar su código moral y su sistema legal a las exigencias de la economía de mercado. (...) El imperio romano sucumbió porque sus ciudadanos ignoraron el espíritu liberal y repudiaron la iniciativa privada. El intervencionismo económico y su corolario político, el gobierno dictatorial, descompusieron la poderosa organización de aquel imperio, como también, en el futuro, lo harán con cualquier otro régimen social (p. 908).

\section{La imposibilidad de los precios máximos}

Al igual que Juan de Mariana criticara en su Tratado y discurso sobre la moneda de vellón, la política de establecimiento de precios máximos, no sólo por considerarla incapaz de conseguir efectos positivos, sino por ser altamente dañina en el proceso productivo - (Mariana, 1987) citado por Huerta de Soto (2010: 57)—, encontramos que también Ibn Jaldún ataca la fijación de precios máximos por la autoridad, explicando que «la bajada de los precios es peligrosa para quienes tienen que mantener su actividad con esos precios bajos». Dejando patente que propiciarlo 
en la ciudad es malo para todo el sector en el cual recaiga una bajada de precios, sea impuesta como medida coactiva, o por una bajada en la demanda del mercado. Es incluso perjudicial para la recaudación de impuestos para el sultán. Y en definitiva, mantener los precios bajos perjudica a quienes comercian con este tipo de artículos abaratados, "porque el beneficio que obtienen es escaso, o insuficiente o inexistente y ello los obliga a desprenderse de sus capitales, con lo que sus condiciones de vida se deterioran y acaban cayendo en la pobreza y en la indigencia». Y denuncia la gravedad de la utilización de precios máximos en las sociedades por un supuesto «interés general», que no es tal, y que de la siguiente manera clarifica. Jaldún (5:12):

Es algo sabido que todo esto ha conducido a construir hábitos arraigados en la población urbana, que tiene por bueno que el precio del grano $y$ de otros productos que hay que comprar sea bajo, debido a la necesidad general que se tiene de ellos, que obliga a todo el mundo, tanto al rico como al pobre a adquirir alimentos. Porque la mayor parte de la población de las ciudades no es autosuficiente y ello hace que los bajos precios les resulten ventajosos y que, en este artículo especialmente, esa ventaja se imponga a lo que sería bueno para el comercio. Dios es el Dueño de todo sustento, el Fuerte, el Firme ${ }^{14}$ (p. 720).

Anteriormente describe en qué consiste el comercio y todo el proceso por el que son perjudiciales los precios bajos máximos; todo un alegato a favor del comercio, plenamente conforme con la opinión de Juan de Mariana y con la tradición liberal de que toda intervención injustificada sobre el mercado viola el derecho natural. Siguiendo con la imposibilidad de los precios máximos en Jaldún (5: 12) leemos:

Esto es así porque, como hemos dicho anteriormente, la ganancia y las formas de ganarse la vida se obtienen con los oficios y con el comercio. El comercio consiste en comprar productos y mercancías y almacenarlos a la espera de que los mercados fluctúen y se produzca un incremento de los precios, que es a lo que se llama

\footnotetext{
${ }^{14}$ Corán, LI, 58.
} 
beneficio. Así se obtiene la ganancia, y ése es el medio de vida de quienes se dedican al comercio de forma permanente. Cuando se mantiene bajo el precio de las mercancías de manera continua$\mathrm{da}$; o baja la demanda de productos alimenticios, o de ropa, o en general de cualquier cosa que represente riqueza, el comerciante no gana nada con la fluctuación de los mercados y desaparece el beneficio y el crecimiento del capital si esa situación se prolonga. El mercado de este tipo de productos se paraliza, los comerciantes pierden todo interés en mantener su esfuerzo y sus capitales se van reduciendo... (p. 719).

Posturas comunes con el austroliberalismo y la Escuela Austriaca de Economía, patente en repetidas ocasiones a lo largo de la Muqaddima. Mises, respecto a la reacción del mercado ante la intervención del gobierno, también comenta los precios máximos en idénticos términos:

Cuando el poder político establece precios máximos para determinado bien de consumo o para una cantidad limitada de tales bienes -en tanto los precios de los restantes factores de producción quedan libres- la elaboración de las mercancías intervenidas decrece. Los empresarios marginales, con objeto de eludir pérdidas, interrumpen la fabricación, (...) Tal resultado es evidentemente contrario al ambicionado por el intervencionista. (...) El fracaso acompaña fatalmente la interferencia en la vida mercantil (1949: 901).

Se aferran a la superstición de que decretar y establecer precios máximos por debajo de los precios que el mercado libre establecería es un medio adecuado para mejorar las condiciones de los compradores. No mencionan la evidencia documental del fracaso de la política del precio justo y de sus efectos, los cuales, desde el punto de vista de los gobernantes que recurrieron a ella, eran menos deseables que la situación previa que trataban de cambiar (1957: 239-240).

Jaldún, continúa extendiendo las explicaciones a todo el proceso social: «... en general, la gente sólo disfruta de un buen medio de vida y obtiene ganancias cuando los precios son moderados y la fluctuación de los mercados es rápida» (p. 720). Y es evidente, que ello sólo se produce en un mercado libre o sin intervencionismo. 
Y lo mismo ocurre cuando los precios son excesivamente altos pues las restricciones gubernamentales y los privilegios especiales, compelen a los consumidores a comprar productos peores a precios más altos.

Por ello, -continúa reflexionando Jaldún- todas las regulaciones e inspecciones suponen siempre gastos, y que estos gastos son siempre un impuesto sobre la mercancía y, como consecuencia, «sobrecargan al consumidor interior y desaniman al comprador extranjero. Tales tasas e impuestos son mayores en los últimos tiempos de la dinastía» (p. 659). Con lo que podríamos relacionar e identificar el aumento de los impuestos con una seña del colapso o fin de una civilización.

\section{Gobierno mínimo: defensa y seguridad. Definición y crítica del monopolio}

Al igual que Juan de Mariana, siguiendo la tradición liberal, deducimos derechos naturales innatos al ser humano de protección, de justicia y defensa que el gobierno debe limitarse estrictamente a procurar a los individuos defendiéndoles contra todas las injusticias denunciadas y garantizándoles «la defensa y la salvaguarda de uno mismo y de su casa». Para ello, Jaldún analiza y expone de la siguiente manera lo que sería el origen y surgimiento natural del gobierno, pero curiosamente refiriéndose sólo a esta mera función de defensa o seguridad. Hemos desarrollado en un capítulo específico la manera en que Jaldún reconoce y denuncia la coacción del gobierno sobre la sociedad y la forma en que este poder autoritario degenera y causa ruina; luego, para este autor, la seguridad es, en sí misma, un sistema de coacción contra el mismo pueblo que pretende proteger. Con parecidos argumentos desarrollarán recientemente eminentes anarcocapitalistas (Hoppe, Hülsmann y Block, 2003) esta tesis pero aportando soluciones innovadoras y alternativas basadas en la provisión de dicha seguridad a partir de empresas privadas distintas al propio gobierno. Sin embargo, sin avanzar en este campo pionero, para Jaldún el gobierno garantiza a cada individuo la posesión de su persona y de sus bienes, y en nombre de esta justicia o garantía 
se justifica su existencia. En ese sentido se pronuncia (1: preliminar I):

Más tarde, una vez que la vida en sociedad ha quedado establecida entre los hombres, como hemos descrito, y la civilización es ya un hecho en el mundo, resulta indispensable un freno que defienda a unos de otros. Porque en el instinto animal del hombre existe la agresividad y la injusticia, y las armas, que fueron hechas para defenderse de las agresiones de los animales irracionales, no sirven entre los humanos para evitar las agresiones entre ellos mismos, ya que todos las poseen. Es necesario, por tanto, otro instrumento que los defienda de la agresividad mutua, y ese instrumento no puede venir de otros seres ya que los demás animales carecen de capacidad para entender sus pensamientos y sus impulsos. Tal freno tiene que ser, por tanto, uno de ellos que tenga sobre los demás dominio, autoridad y poder para que ninguno pueda ejercer su agresividad contra un semejante. $Y$ ése es el sentido del poder-real, que constituye un rasgo específico del hombre y le es absolutamente necesario (p. 71).

Comprobando en las fuentes islámicas este concepto, confirmamos por un comentario de Muhammad Asad al pasaje del Corán (5:38) que, aunque existe un principio fundamental de la Ley Islámica según el cual no se impone al hombre un deber (taklif) sin concederle un derecho (haqq) correspondiente, sin embargo, uno de los derechos inalienables de todo miembro de la sociedad islámica — sea o no musulmán- es el derecho a la protección de la comunidad. Es decir, garantizar un mínimo de bienestar material y de seguridad — no sólo necesidades espirituales sino físicas e intelectuales- acorde a un nivel de vida equitativo que sea proporcional a los recursos de que dispone la sociedad: ese mínimo de bienestar material y de seguridad según el cual no puede haber dignidad humana, ni libertad real en definitiva (Asad, 2001: 147). E, Ibn Jaldún (3: 22, p. 326), identifica en su obra que la protección de los habitantes del país es la última razón de ser de la autoridad, que ha de tratar a los ciudadanos con benignidad.

En cuanto a la concepción del monopolio, en una idea recogida del famoso artículo La ilusión del precio de monopolio de Rothbard y leída en Huerta de Soto (1986: 184), el monopolio actual responde 
a una de las definiciones rothbardianas, la misma que la de Lord Coke, en la forma de grupos de poder favorecidos por el gobierno. Según el gran jurista del siglo XVII, un monopolio es el privilegio o concesión del rey a una persona o institución corporativa. Como detalla Jaldún (4:16) en el epígrafe «que trata de cómo las personas ricas de las ciudades tienen necesidad de rango y protección»:

Esto es porque la persona asentada en una ciudad, cuando su riqueza se hace cuantiosa y son muchas sus fincas y sus haciendas, y pasa a ser una de las personas más ricas de la ciudad, las miradas se vuelven hacia él. Su situación de lujo y bienestar se extiende de manera que puede competir con la de los emires, y éstos se sienten molestos porque en la naturaleza humana se asienta la hostilidad. Sus ojos se dirigen hacia lo que posee y tratan de apropiárselo utilizando para ello todas las artimañas posibles. Llegan incluso a usar el lazo de las normas gubernativas, o bien lanzan acusaciones de las que se aprovechan abiertamente para desposeerlo de su riqueza. Las normas gubernativas son, por lo general, injustas... porque la justicia genuina sólo existió en el califato que se atuvo a las leyes religiosas, que fue de corta duración tal como dijo el Profeta —Dios lo bendiga y lo salve-: «Tras mí, el califato durará treinta años, y luego retornará el poder-real despótico» ${ }^{15}$. Y siendo esto así, resulta obvio que quien posee dinero y riquezas conocidas en la sociedad en la que vive, necesitará una guardia que lo defienda, o algún personaje de alto rango de entre los parientes o íntimos del rey, o un grupo familiar al que el sultán tenga respeto y a cuya sombra pueda acogerse y vivir en su confianza, libre de ataques enemigos. Si no posee esto, se verá convertido en presa y víctima de engaños y triquiñuelas legales. Dios decide, nadie puede oponerse a su decisión. ${ }^{16}$ (p. 667).

15 Ludwig von Mises opina en conformidad que «los dirigentes de los ejércitos mahometanos que, en un lapso increíblemente corto, conquistaron buena parte del área del Mediterráneo, no tenían una fe fatalista en Alá» ... «el letargo que más tarde se apoderó de los pueblos islámicos no fue causado por el fatalismo de su religión. Fue el despotismo lo que paralizó la iniciativa de sus súbditos. Los toscos tiranos que oprimían a las masas ciertamente no eran ni letárgicos ni apáticos. Eran infatigables en su búsqueda del poder, la riqueza y el placer» (Mises, 1957: 122 y 123).

16 Corán XIII, 41. 
Y es que, «todos los políticos, todos los gobiernos, los reyes lo mismo que las repúblicas, recelaron siempre de la propiedad privada» (Mises, 1927: 89). Entonces, ¿qué lleva al origen de este privilegio, comienzo del monopolio? El mismo instinto o la necesidad de seguridad y protección de la propiedad y de la vida contra el carácter usurpador y corrupto del gobierno por falta de políticos honestos. No es mercado libre el que conduce a esta formación, idea o falacia originada en Karl Marx ${ }^{17}$, que Jaldún comprende pues critica su concepción de la mano del poder. Este monopolio que se inicia con la participación del gobierno y sus grupos afines en el comercio conlleva consecuencias críticas para toda la economía, que Jaldún (3:38) aprecia cuando denuncia que:

La actitud de los príncipes y personajes poderosos de los países que se dedican al comercio y a la agricultura siempre desemboca en lanzarse a comprar las cosechas y las mercaderías de los propietarios que llegan a sus territorios, fijando el precio que se les antoja, y vendiéndoselas inmediatamente a los súbditos que están bajo su poder al precio que quieren fijar. Esto es más grave que lo anterior [que el sultán entre en el comercio], más dañino para los súbditos y deteriora todavía más su situación. Y ocurre con frecuencia que el sultán es empujado a ello por quienes lo han hecho entrar en esos gremios - quiero decir, comerciantes y agricultores - al ver que esta es la actividad con la que han prosperado. Llevan al sultán a ella y la ejercen junto a él, pero pensando en su propio beneficio y sin más objetivo que el de acumular riquezas con rapidez, obteniéndolas especialmente por medio de la práctica del comercio sin pagar impuestos ni aranceles, pues ésta es la manera más eficaz de incrementar la riqueza y la forma más rápida de obtener beneficios. De lo que no se dan cuenta es del daño que causan al sultán al provocar que descienda la recaudación. Convendría al sultán guardarse de estos tales y precaverse de

17 La falaz idea de unos pocos monopolistas controlando la economía reduciendo al resto a meros trabajadores (Mises, 2010: 143-191). Ibn Jaldún tiene claro que este «monopolio» u «oligopolio» surge del propio gobernante que bloquea a todos los competidores y nuevas empresas para que no entren a un sector determinado y que no pueden competir en igualdad de oportunidades contra los mercaderes afines al sultán y sus privilegios. Con lo que está definiendo un monopolio coercitivo. 
sus intrigas, tan perjudiciales para sus ingresos como para su autoridad. Dios - alabado y ensalzado sea- inspire en nuestras almas la buena dirección y nos beneficie con la corrección de nuestras acciones. No hay más Señor que Él (pp. 497-498).

Luego toda licencia a favor de grupos privilegiados dentro o cercanos al poder, supone un riesgo de deterioro de la sociedad y de decadencia de la dinastía como consecuencia del decaimiento y la disminución de la recaudación - «porque es impensable que se le vaya a cobrar aranceles al sultán, mientras que si fueran otros los que realizaran aquellas operaciones, todo el beneficio que se produjera engrosaría en la recaudación»- y porque la desventaja del resto de agricultores y comerciantes en competencia frente a dichos grupos monopolísticos hace que aquellos pierdan su capital, "y les imposibilita seguir en el mercado" acabando con sus ahorros; $y$ "cuando esto se repite y ocurre con frecuencia hace que las pérdidas, los apuros económicos y la disminución de beneficios afecten a los súbditos, y eso provoca que desaparezca totalmente el estímulo en esforzarse en esa actividad»... (3:38, p. 496). Y en el mismo sentido Mises (2010: 179):

Las leyes que obstaculizan a los principiantes con talento son perjudiciales a los intereses de los consumidores, pero protegen a quienes ya han afianzado su posición en el comercio frente a la competencia de los intrusos. Al hacer más difícil para un comerciante obtener beneficios y al poner impuestos sobre la mayor parte de los beneficios obtenidos, esas leyes evitan la acumulación de capital por los recién llegados, ...

En el siguiente pasaje $(5,11)$ en el que Jaldún trata del acaparamiento, denuncia ciertas prácticas abusivas del comercio y después, pone un ejemplo que esclarece su total desacuerdo con que el comercio pueda ser motivo de imposición o gravamen:

Es algo bien conocido entre las personas avisadas y con experiencia de las ciudades que acaparar grano a la espera del momento en que suban los precios es algo funesto que puede tener como consecuencia la pérdida y la ruina de los beneficios. La causa de 
ello es - pero Dios es más sabio- que la gente tiene necesidad ineludible de alimentos, y ello les obliga forzosamente a dar su dinero a cambio de ello. Pero sus espíritus permanecen apegados al dinero, y ese apego de sus espíritus a lo que poseen hace que deseen un gran mal a quien se lo toma sin darles nada a cambio. Tal vez sea eso lo quiso expresar el Legislador ${ }^{18}$ cuando habla de tomar las riquezas de la gente gratuitamente. Y en el caso que nos ocupa, aunque no sea sin dar nada a cambio, el hecho de que los espíritus muestren apego por el dinero y se vean obligados a darlo forzosamente, sin posibilidad ninguna de evitarlo, es una especie de exigencia forzada. Cuando se trata de alimentos o comestibles, la gente también compra las demás cosas, pero no por obligación, sino porque la variedad de los gustos los empuja a ello. Y el dinero que dan a cambio de ellas lo dan porque quieren y porque les apetece, y no mantienen aquel apego por lo que han dado como pago. Por eso es algo bien conocido que el acaparamiento concita las fuerzas psíquicas contra quienes lo practican, porque la gente siente que se les arrebata su dinero. Y eso es lo que puede hacer que desaparezca el beneficio, pero Dios es más sabio (p. 717).

Mises (1927: 117) podría señalar lo mismo si en la actualidad existiera «un bien imprescindible para la supervivencia humana, irremplazable por sustitutivo alguno, en el sentido más literal y absoluto».

Por todo lo anterior, identificamos a Ibn Jaldún como un pensador precursor del liberalismo al estar sus tesis perfectamente integradas dentro de la posterior corriente del liberalismo económico, al defender que los problemas para el desarrollo de las civilizaciones surgen cuando no se respetan las instituciones tradicionales de la propiedad privada, la función empresarial y los mercados, tan necesarios para el progreso de la sociedad.

18 El Profeta del Islam. 


\section{III \\ IBN JALDÚN Y LA ESCUELA DE SALAMANCA: ANTECEDENTES DE LOS PRINCIPIOS TEÓRICOS DE LA ESCUELA AUSTRIACA}

Además de los elementos básicos del austro-liberalismo que a lo largo de toda la Muqaddima se han analizado para clasificar el pensamiento de Jaldún como precedente de la economía de mercado, referimos ahora la génesis de algunos principios teóricos que específicamente se considerarán después originales de la escolástica del Siglo de Oro Español (Chafuen, 1991; y Huerta de Soto, 2010), apreciando las raíces de la concepción dinámica y subjetivista de la economía en la percepción jalduniana que prueba algunos de los fundamentos económicos sobre los que se asentarán los principios teóricos de la Escuela Austriaca de Economía.

\section{Concepto dinámico de competencia, determinación de los salarios e implicaciones básicas del subjetivismo sobre la teoría económica}

Descubrimos en Jaldún el concepto dinámico de competencia entendida como un proceso de rivalidad entre vendedores - que posteriormente preconizan Castillo de Bovadilla y Luis de Molina (Huerta de Soto, 2010: 53)_, precisamente a través de un razonamiento de rivalidad entre empresarios para explicar la subida de de los salarios, que al mismo tiempo refutaría la teoría del valortrabajo marxiana o socialista de explotación. Lo hace incluyendo también la influencia del mercado: número de demandas - valoración subjetiva del bien por parte de los compradores- y, por otro, el número de bienes a la venta - con conceptos o factores de abundancia y escasez de riqueza- descrito en poblaciones mayores o menores. Reproduciendo a Jaldún (4: 12):

En lo referente a manufacturas y trabajos ajenos, también son caros en las grandes ciudades con amplio desarrollo social. Las causas de estos altos precios son tres. La primera, la gran necesidad que 
de ellos se tiene debido a la mucha población que en ellas hay. La segunda, que los trabajadores ponen un alto precio a sus servicios y al ejercicio de sus oficios debido a la facilidad de la vida en la ciudad, causada a su vez por la abundancia de alimentos. Y la tercera, el gran número de personas pudientes y la necesidad que tienen de emplear a otros y de requerir los servicios de artesanos capacitados. Por tales servicios pagan a los trabajadores más de lo que su trabajo vale, a causa de la rivalidad y de la pretensión de tener sus servicios en exclusiva. Los trabajadores, los artesanos y los menestrales se vuelven entonces arrogantes y suben el precio de sus trabajos y, como consecuencia de ello aumentan también los gastos de los habitantes de la ciudad (p. 658).

Con la puja de los empresarios o demandantes de servicios y su rivalidad por hacerse con los mismos, Jaldún intuye y se anticipa al modelo del concepto dinámico de competencia que Raymond de Roover (Huerta de Soto, 2010: 54) atribuye a Luis de Molina entendido como «proceso de rivalidad entre compradores que tiende a elevar el precio». En consecuencia Mises (1949: 707) expresa que la rivalidad o «la competencia que entre los patronos se plantea por conseguir la mano de obra apropiada no es menos dura que la que entre ellos se suscita al pujar por las materias primas, las máquinas (...)». Es a lo que se refiere Jaldún con «por tales servicios pagan a los trabajadores más de lo que su trabajo vale, a causa de la rivalidad y de la pretensión de tener sus servicios en exclusiva». Y continúa Mises, que el patrono paga a sus asalariados el valor que el mercado atribuye a los servicios que le prestan, o lo que es lo mismo «que prevalece en el mercado una insoslayable tendencia a que los salarios se igualen con el valor del correspondiente producto marginal». Por su lado, Jaldún da cuenta de que debido a su escasez, con una inteligencia y destreza mayor, los artesanos tenderán a demandar en el mercado un precio o salario más alto puesto que éstos «se vuelven arrogantes» y piden «más de lo que su trabajo vale» obviando los costes y sorteando la posterior teoría del valor-trabajo. Huerta de Soto (1994: 193) en su capítulo ¿Es el trabajo una mercancía? destaca «como las leyes económicas más importantes, en primer lugar, «la ley de la oferta y la demanda...», ley de oferta y demanda que Jaldún explica con tres puntos: «La primera, la gran necesidad 
que de ellos se tiene debido a la mucha población que en ellas hay. La segunda, que los trabajadores ponen un alto precio a sus servicios y al ejercicio de sus oficios debido a la facilidad de la vida en la ciudad, causada a su vez por la abundancia de alimentos. Y la tercera, el gran número de personas pudientes y la necesidad que tienen de emplear a otros y de requerir los servicios de artesanos capacitados». Continúa Huerta de Soto: «...y, en segundo lugar, la que asegura que "el salario está determinado por el valor descontado de la esperada productividad marginal del trabajo" ", ya comentado: el pago sería ajustado por vendedores y compradores, y dependería de la productividad esperada de lo que se produjera.

Concretándolo, contemplemos a Ferdinando Galiani (1728-87) en la tradición escolástica franco-italiana tardía, que describía de forma similar a Jaldún cómo la utilidad de los productos y la escasez de diversos tipos de trabajo determinan los precios del trabajo en el mercado: "Yo creo que el valor de los talentos humanos se determina igual que el de las cosas inanimadas, y que se rige por los mismos principios de escasez y utilidad combinados...» (Rothbard, 1995: 449).

Ibn Jaldún entiende que la utilidad subjetiva de un bien disminuye a medida que se incrementa su oferta: la mayor abundancia de un bien depara un menor valor y viceversa, y cómo el valor-estima para los consumidores cambian rápidamente en el mercado. En el futuro sólo se añadirá el concepto de «unidad marginal» para completar la teoría. También puede percibirse que los valores subjetivos de los bienes, los valores-estima para los consumidores, cambian rápidamente en el mercado. Jaldún, acabamos de demostrar, no se confunde con la teoría del valor-trabajo - que considera que el valor de un bien viene determinado por la cantidad de trabajo que lleva incorporado- sino que deduce que el valor del trabajo, al igual que ocurre con el resto de mercancías, está sujeto a la ley de la oferta y la demanda y a la apreciación o valoración de sus productos por parte de los demandantes, constatando que son los precios los que determinan los costes, y no al revés, evidenciando el carácter subjetivo de los costes por parte del actor. Es decir, no son los costes del trabajo lo que determina el valor, sino lo contrario: es el valor lo que determina los 
costes del trabajo. Y, como detallaremos, en consonancia resuelve la paradoja del valor.

Continuando con las implicaciones básicas del subjetivismo sobre la teoría económica, es Diego de Covarrubias y Leyva (1512-1577) quien anticipa la correcta concepción de la esencia de la teoría subjetiva del valor sobre la que gira todo el entramado del análisis económico de la Escuela Austriaca, al afirmar que «el valor de una cosa no depende de su naturaleza, objetiva sino de estimación subjetiva de los hombres aunque esta sea alocada» (Cobarrubias, 1604: 132) citado en Huerta de Soto (2010: 54). Hemos apreciado, y matizado, que Jaldún lo advierte al afirmar que a los trabajadores «se le pague más de lo que su salario vale» o del valor de lo que producen, refutando o esquivando así la posterior teoría del valor-trabajo y llegando a la teoría subjetiva del valor. En el mismo sitio Huerta de Soto cita a Luis Saravia de la Calle en su Instrucción de mercaderes de 1544 porque expone la verdadera relación entre los costes y los precios explicando que «los que miden el justo precio de la cosa según el trabajo, costas y peligros del que trata o hace la mercadería yerran mucho; porque el justo precio nace de la abundancia o falta de mercaderías, de mercaderes y de dineros, y no de las costas, trabajos o peligros» (Saravia de la Calle, 1949:53). O en cita de Jaldún «la gran necesidad que de ellos se tiene debido a la mucha población que en ellas hay... que los trabajadores ponen un alto precio a sus servicios y al ejercicio de sus oficios debido a la facilidad de la vida en la ciudad, causada a su vez por la abundancia de alimentos... el gran número de personas pudientes y la necesidad que tienen de emplear a otros y de requerir los servicios de artesanos capacitados...»y continuando con el ya comentado concepto dinámico de competencia y con la refutación de la teoría del valor-trabajo.

\section{La paradoja del valor}

Abordamos ahora lo que tanto daño y confusión ha traído a los fundamentos de la ciencia económica y que Jaldún razona acertadamente: la teoría del valor -y la relación o paradoja entre el valor de los bienes de lujo y los de primera necesidad-, que con 
posterioridad han intentado resolver otros pensadores como Nicolás Copérnico, John Locke o John Law, y que después comentó Condillac, demostrando su superioridad sobre Adam Smith -que fue incapaz de resolverla-, tema por fin zanjado por Jaime Balmes. Aunque es Carl Menger, quien refiriéndose a «la objetivación del valor de los bienes, que es por su propia naturaleza totalmente subjetivo", sentencia la medida más primordial del valor de los bienes, «la significación que nosotros damos a la satisfacción de nuestras necesidades» (Menger, 1871: 179).

Efectivamente, Huerta de Soto (2002: 261) matiza que ya veintisiete años antes que Carl Menger, Jaime Balmes fue capaz de resolver esta "paradoja del valor» y de enunciar claramente la teoría de la utilidad marginal. Leamos en el estudio de León Gómez Rivas un resumen del texto donde Balmes (1925) se pregunta:

«(...) ¿Cómo es que vale más una piedra preciosa que un pedazo de pan?» Y contesta: «No es difícil explicarlo; siendo el valor de una cosa su utilidad... si el número de unidades de los medios aumenta, se disminuye la necesidad de cualquiera de ellos en particular; porque pudiéndose escoger entre muchos no es indispensable ninguno. $Y$ he aquí por qué hay una dependencia necesaria entre el aumento y disminución del valor, y la carestía y abundancia de una cosa» (p. 339 y ss.).

Si junto con Menger y Balmes fueron Cantillón, Turgot y Say continuadores de la tradición subjetivista comenzada por nuestros escolásticos españoles del Siglo de Oro, ¿por qué no se podría calificar de antepasado o precedente de la misma corriente o al menos de la teoría subjetiva del valor a Jaldún analizando el fragmento que a continuación relacionamos? Jaldún (4:12):

Cuando una ciudad crece y su población aumenta, bajan los precios de los alimentos de primera necesidad y de lo que se usa para condimentarlos, mientras que suben los de los lujosos como especias, frutas y demás. Y cuando la población de una ciudad disminuye y su actividad social es escasa, sucede lo contrario. La causa de esto es que el grano es un alimento indispensable y, por ello, la demanda que de él se hace es muy amplia, ya que nadie deja de proveerse, para sí y para su casa, del alimento necesario para un mes o para un año. Y esto 
se extiende necesariamente a toda la población de la ciudad o a la mayor parte de ella, en esa ciudad y sus alrededores. Y todo el que se procura alimento acopia mucho más de lo que necesita para sí mismo y para su familia, de manera que sería suficiente para atender a las necesidades de una gran parte de la población de esa ciudad. Los alimentos de primera necesidad exceden entonces, obviamente, a los que necesita la población de la ciudad, y por ello bajan los precios por regla general, salvo en determinados años en los que se ven afectados por daños meteorológicos. Si la gente no mantuviera almacenado el grano para cuando se vea afectada por esos daños, aquel se daría gratis y a cambio de nada, dada la gran cantidad existente, correspondiente a la numerosa población (p. 657).

Jaldún revelando que la utilidad disminuye en función de la abundancia, contribuye a resolver la paradoja del valor igual que Balmes: el grano, a pesar de su necesidad y de la multitud de placeres que aporta al hombre, no se considera algo valioso - «se daría a cambio de nada» al igual que el aire, el pan y el agua, muy útiles para la vida humana, no tienen valor porque no escaseanen un país bien surtido y el hombre no trata de hacerse dueño del mismo porque la abundancia de ese elemento le permite encontrarlo por doquier en torno suyo.

Y continúa y se anticipa a la utilidad marginal decreciente con unidades de bienes de alimentación de distinto lujo: cuando la población es escasa tiene hambre, valora más el grano que «las especias, las frutas y cosas semejantes»; pero si este apetito queda satisfecho - «cuando la sociedad se ha desarrollado ampliamente y ha aumentado la población»—- serán las especias y demás alimentos lo que se vuelva valioso para ella. Prosigue:

En cuanto a las cosas que hacen la vida más agradable, como son las especias, las frutas y cosas semejantes, al no ser estrictamente necesarias, su obtención no absorbe el trabajo de toda la población de la ciudad, ni siquiera de la mayor parte de ella. Pero cuando la sociedad se ha desarrollado ampliamente y ha aumentado la población y la actividad social, y los elementos de lujo son abundantes, aumentan las exigencias en la demanda de esas comodidades y el deseo de poseer muchas de ellas, cada cual según su situación. Las existencias entonces resultan insuficientes para atender a la demanda, pues son muchos los que desean obtenerlas mientras 
que ellas mismas son escasas. Crece el interés, y los ricos y los amantes del lujo pagan por ellas precios desorbitados, porque sienten mayor necesidad de poseerlas que los demás. Los precios entonces suben, como bien puede entenderse. (pp. 657-658).

Como vemos en varias citas, Jaldún comprende la concepción subjetiva en que el valor de una cosa no depende de su naturaleza objetiva o costes normales sino de la apreciación subjetiva de los hombres pues llegan «a pagar por ellas precios desorbitados [y excediendo sus costes] porque sienten mayor necesidad de poseerlas que los demás», por el elevado interés de los ricos que las demandan. Entonces, expresado como los «precios de los bienes de primera necesidad y de lujo» nos recuerda el famoso caso de los «diamantes y el pan», pues acierta al explicar en el texto porqué los diamantes o bienes de lujo valdrían más que el pan -ya que los artículos de primera necesidad exceden... y se podrían dar por nada»-, atendiendo al ejemplo concreto de ciudades con mayor población. Y explica, cuándo no vale gran cosa un bien de lujo en poblaciones menores, revelando que los costes vienen determinados por el valor que un bien posee para consumidor y no al revés:

En las ciudades pequeñas con escasa población también son escasos los alimentos debido a que es poco el trabajo que a ello se puede dedicar, y a la previsión de lo que, habida cuenta de la pequeñez de la ciudad, sucedería si faltasen alimentos. Por eso toman lo que pueden llegar con sus manos y lo almacenan, pues su posesión es algo de extrema importancia para ellos. Y para quien desea adquirirlo, el precio es muy alto. Pero las cosas no indispensables tienen poca demanda entre ellos debido a que son pocos y de condición humilde. El mercado de estos productos es poco activo y su precio es particularmente barato (pp. 658-659).

En ciudades más pequeñas y pobres consideramos primordial el valor de los bienes básicos para la subsistencia, dada su escasez, - o en locución mengeriana- que la significación que estos ciudadanos dan a la satisfacción de sus necesidades primarias son altas, esenciales y preferidas sobre otras necesidades superfluas o secundarias representadas en productos de lujo u ostentación 
poco sugestivos para aquellos, que así, casi no se demandan ni comercializan y «su precio es particularmente barato».

\section{La naturaleza dinámica del mercado, los precios, la utilidad y la escasez}

Queremos demostrar que Jaldún explicó que el valor de los bienes es una apreciación subjetiva de los consumidores. Juan de Lugo (1583-1660) preguntándose cuál debe ser el precio de equilibrio no dio respuesta argumentando «que depende de tan gran cantidad de circunstancias específicas que sólo Dios puede conocerlo», citado en Huerta de Soto (2010: 56) tomado a su vez de Lugo (1642: vol. II, 312); y en el mismo sitio y sentido Salas (1617: 4, n.․․ 6 , 9). Tampoco Jaldún reivindica un precio de equilibrio o recomendable, o que éste deba ser conocido; todo lo contrario, sólo estudia las causas y el sentido de sus oscilaciones, es decir, un precio indeterminado pero que resulta del sometimiento a las fuerzas de la ley de la oferta y la demanda, teniendo en cuenta el valor de los bienes como una apreciación subjetiva de los consumidores. Luego no existe un verdadero precio hacia el que tienda o deba tender el mercado, sino que siempre oscilará —y de ahí su dinamismo-, en función de los factores antes analizados, es decir, de la escasez, la abundancia y la apreciación subjetiva o estima que de un artículo se tenga. Sirviéndose del ejemplo del transporte de mercancías por los comerciantes y el riesgo que conlleva, Jaldún $(5,10)$ aclara:

El transporte de mercancías desde países que están a gran distancia y en cuyos caminos exista un gran peligro será más ventajoso para el comercio, serán mayores los beneficios y se correrá menos riesgo ante las fluctuaciones de los mercados. Porque las mercancías transportadas serán pocas y éstas en pequeñas cantidades debido a la lejanía del lugar de procedencia y al gran peligro del camino. Eso hace que sean pocos los que se arriesguen a transportarlas y eso hace difícil encontrarlas. Y esa escasez y esa dificultad hacen que se eleven los precios. Pero cuando el país está a poca distancia y el camino es muy frecuentado, debido a su seguridad, son muchos los que transportan, por lo que los productos son abundantes y los precios se abaratan... (p. 716). 
Jaldún, defendía una teoría del valor basada en la utilidad subjetiva: La fuente de valor de un bien es su utilidad en tanto que estimada por los individuos de acuerdo con sus necesidades, deseos y su capacidad para satisfacerlos: utilidad y demanda, determinan el valor de un bien. La utilidad de los bienes se incrementa con su escasez y decrece con su abundancia. Sin embargo, explica de qué manera y en qué situaciones existe una influencia de los gastos en los precios, pero entendiendo que ello se debe a situaciones muy especiales de tiempo y lugar. Jaldún (4:12):

También influyen en el precio los gastos de la labor agrícola, que quedan reflejados en el precio de aquellos. Esto es lo que ocurre actualmente en el al-Andalus porque, cuando los cristianos empujaron a sus habitantes hacia la orilla del mar, de manera que quedaron en una tierra abrupta, difícil para la siembra e inapropiada para las plantas, mientras ellos se quedaban con el suelo fértil y la tierra buena, se vieron obligados a trabajar los campos y las fincas para mejorar las plantas y la agricultura. Este trabajo requería costosas labores y productos como abonos y otros que suponían una carga adicional. Esto hacía que en la labor agrícola se produjeran unos gastos considerables que eran tenidos en cuenta en el precio de los productos. La región de al-Andalus resulta por ello especialmente cara desde que los cristianos empujaron a sus habitantes hacia esas regiones costeras dominadas por el Islam. La gente supone, cuando oye hablar de los altos precios en esta región, que son debidos a la escasez de alimento y de grano en esa tierra, pero no es así. Sabemos que son gentes diestras en las labores agrícolas y de los más dedicados a ellas... (pp. 659-660).

Por todo lo argumentado debe entenderse que se trata de productos agrícolas indispensables, cosas que no tiene valor porque cuesten, sino que cuestan porque tienen valor, y que la causa del valor no es el trabajo, sino el valor de lo que trae el trabajo.

\section{La teoría cuantitativa del dinero}

Por otro lado, en el capítulo V de al-Muqaddima, Jaldún explica con todo lujo de detalles que «la ganancia no es más que el valor 
del trabajo: cuando aumentan los trabajos que se realizan, aumenta el valor que por ellos obtienen quienes lo llevan a cabo...» (5: 1, p. 692). Esto nos lleva a enlazar con la teoría cuantitativa del dinero.

Atendiendo a esta teoría, los maestros de la Escuela de Salamanca vivieron el tiempo de la inflación del oro y plata americanos y teorizaron sobre la utilidad, la preferencia subjetiva y la escasez. En concreto, Rothbard (1995, p. 242) cita al escolástico español Martín de Azpilcueta ${ }^{19}$ que estableció «doce años antes que Bodino", la causa de la elevación de los precios en el aumento de metal procedente de América. O actualmente, lo que resulta análogo citando a Fisher (1930: 328) en dicho sentido «que cuando el dinero escasea el valor o el precio del dinero, su poder de compra, aumenta y cuando el dinero abunda el valor o precio del dinero, su poder de compra disminuye» y de forma más detallada profundiza diciendo que «lo que resulta análogo al precio del trigo no es el tipo de interés sino el valor del dinero, o lo que es lo mismo, su poder para adquirir otros bienes» ${ }^{20}$. Por su lado, podemos incluir a Jaldún en la comprensión de la teoría cuantitativa en varias ocasiones, como cuando corrige y niega la creencia popular de que los pueblos son más ricos según el número de propiedades y de riquezas que poseen, declarando que ello es a causa de su mayor población y su correspondiente número de trabajos. Copiando a Jaldún (5: 11):

Sabemos que actualmente la situación en El Cairo y en Misr [Egipto], en lo que a lujo y riqueza de sus habitantes se refiere, es algo que provoca asombro, hasta el punto de que muchos de los pobres de al-Magrib deciden trasladarse a Egipto a causa de ello, cuando llega a sus oídos que la situación de confort de Egipto es mayor que la de ningún otro lugar. El vulgo está convencido de que esto se debe a que la gente de esas comarcas disfruta de más

19 Y previamente a él Copernico en su libro Monetae cudendae ratio. Pero en opinión de Huerta de Soto (2010) quién con posterioridad mejorará el análisis sobre la teoría cuantitativa del dinero de Azpilcueta (1965) y Copérnico será Mariana en su citado Tratado y discurso sobre la moneda de vellón.

${ }^{20}$ Aclarando que «el tipo de interés es el precio pagado por disponer dinero en el presente en lugar de en el futuro y en ese sentido nada tiene que ver con el precio del trigo». 
ventajas que las de otros lugares, o a que tienen riquezas atesoradas, y que son más caritativos y generosos que los de todas las demás ciudades. Pero no es así, sino que esto se debe solamente, como es sabido, a que la población de Misr y de El Cairo es mayor que la de esas poblaciones que se han mencionado, y por eso su situación es más holgada.

Lo que se produce y lo que se gasta siempre está equilibrado en todas las ciudades, de manera que si aumentan los ingresos se incrementarán también los gastos, y viceversa. Y cuando ambos -ingresos y gastos - son cuantiosos, la situación de la ciudad mejora y prospera. ${ }^{21}$ Ninguna de estas cosas admite réplica y deben interpretarse como consecuencia de la abundancia de la población y del aumento de ingresos que se produce en razón de ello, lo que, a su vez, permite gastar y proporciona beneficios a quienes en ello se esfuerzan (pp. 655-656).

Constatamos una vez más que anticipa la teoría cuantitativa del dinero, cuando resalta que la causa de la riqueza no es por sus tesoros sino por su gran número de habitantes y consiguiente cantidad disponible de trabajo en la explicación del motivo de la opulencia de los países que se encuentran entre los más ricos del mundo; idea contraria a la creencia malthusiana de que el exceso de población no se podría emplear productivamente... Reproducimos la Muqaddima (4:14) donde se lee, acerca de los relatos y dichos sobre las grandes riquezas y holguras de diversos países y su gente, que:

(...) La gente común que los escucha supone que eso es debido a que poseen muchas riquezas porque las minas de oro y plata son muy abundantes en sus tierras, o porque se apoderaron ellos solos del oro de los pueblos antiguos, pero no es así. Las únicas minas que conocemos en esas regiones son las del País de los Negros, que está cerca de

${ }^{21}$ El dinero ahorrado, por tanto, no está perdido; regresa a la circulación. Este comentario parece advertir la ley de Say de que la oferta crea su propia demanda que, por otro lado, ya revelara Turgot, al desarrollar un comentario sobre el escrito de Saint-Péravy, con el que amplió su análisis sobre el ahorro y el capital refutando «los temores prekeynesianos de los fisiócratas de que el dinero no gastado en consumo escapa de la corriente circular, y de este modo perjudica a la economía» haciendo bajar los precios (Rothbard, 1995: 438). 
al-Magrib. Además, todos los productos de su tierra los exportan a otros países por medio del comercio; y si tuvieran riquezas disponibles y abundantes, no exportarían sus productos a otros lugares para obtener dinero a cambio de ellos ya que no necesitarían las riquezas de la gente (pp. 662-663).

Resumiendo la ley de Say, «las mercancías se pagan en última instancia no con dinero, sino con otras mercancías» (Mises, 1950). Y, en este sentido, encontramos que Hume (1982: 55) lo expresa de la siguiente manera:

El dinero no es, propiamente hablando, una mercancía; es solamente un instrumento para el negocio, y por unánime acuerdo se convino que serviría para facilitar el cambio de una mercancía por otra. No es la rueda del comercio, pero si la grasa que hace que se mueva con más facilidad. Si consideramos cada reino de por sí, es evidente que más o menos el dinero no tiene demasiada importancia, puesto que el precio de las cosas está siempre proporcionado a la cantidad de moneda...

Jaldún considera el dinero como un objeto de comercio, una forma de riqueza y un conservador de valor «que son el oro y la plata, con lo que se fija el valor de todo lo que se considera riqueza» (p. 692), y en definitiva, el dinero posee un valor porque cualquier valor se cambia en el comercio por dinero, lo que lleva a un término común o patrón monetario y también es un indicio de enriquecimiento; esta idea aparece de nuevo en la teoría que reafirma en otro lugar dentro de la creencia del ahorro como origen y fuente de la riqueza que será una concepción clave en la teoría austriaca el ahorro considerado un factor esencial en la inversión para el desarrollo económico. Dentro del contexto (5: 1):

Ambos [oro y plata] son lo que preferentemente la gente de la tierra quiere atesorar. Y aunque en algunas ocasiones deseen atesorar otros productos, sólo es con la intención de obtener aquellos dos, porque los demás están sujetos a las fluctuaciones de los mercados, mientras que éstos dos están libres de eso y por ello son la raíz de lo que genera beneficios, de los bienes y de los tesoros (p. 692). 


\section{Concepción evolutiva de las instituciones y la metodología de estudio de la historia}

Hayek (1988: 54), nos recuerda en La fatal arrogancia, que «... a través de la ciencia económica podemos establecer... las razones por las cuales las normas evolutivamente establecidas tienden a favorecer la supervivencia de nuestra especie».

Federico Carlos Savigny (1779-1861) es la figura central de la Escuela Histórica del Derecho y uno de los principales juristas de todos los tiempos. Huerta de Soto descubre que es heredero junto una tradición anterior que se remonta desde los grandes jurisconsultos de la Roma clásica hasta Carl Menger pasando por los escolásticos. Martínez Meseguer (2006: 107-114) propone esta escuela, frente a aspectos racionalistas extremos y constructivistas que rechazan de plano todo lo que significa tradición y que encorseta la realidad con rígidos esquemas matemáticos; pues la Escuela Histórica del Derecho, proclama el carácter histórico del Derecho y, por tanto, la necesidad de que sea descubierto y aprendido a través de las manifestaciones de lo que denominaron «espíritu» del propio pueblo (el llamado Volksgeist), ${ }^{22}$ idea parecida a la planteada por Jaldún como veremos, rompiendo al mismo tiempo un tópico de la historia que Mises (1957) constata y reafirma escribiendo al respecto en la siguiente cita:

Sólo en la época de la Ilustración algunos filósofos eminentes abandonaron los métodos tradicionales de la filosofía de la historia y dejaron de preocuparse por los propósitos escondidos de la Providencia, que dirigen el curso de los acontecimientos. Inauguraron una nueva filosofía social completamente diferente de la llamada filosofía de la historia. Concibieron los acontecimientos humanos desde el punto de vista de las finalidades perseguidas por los hombres que actúan, en vez de hacerlo desde el punto de vista de los planes atribuidos a Dios o a la naturaleza (p. 197).

Sin embargo, podemos encontrar un valioso antecedente de esta teoría vigente desde Plutarco, ya resuelta por Ibn Jaldún en 1379

22 Vemos a Mises (1957: 216) disintiendo en pequeños matices respecto del Volksgeist. 
adelantándose a la ilustración y a la corriente racionalista al menos tres siglos, pero por desgracia pasando desapercibida hasta hoy:

Pero los filósofos van más allá en esta argumentación cuando tratan de justificar la profecía con pruebas racionales, y dicen que se trata de una particularidad específica del ser humano. La llevan al límite afirmando que a la Humanidad le es absolutamente necesaria una autoridad que sirva de freno, y añaden a continuación que tal autoridad es la que representa la ley divina, prescrita por Dios y proclamada por un miembro de la comunidad, que necesariamente ha tenido que ser distinguido de los demás con señas particulares que Dios le ha otorgado, para que les señale su camino, se le sometan y le acepten. Y así, la ley acaba por establecerse entre ellos y la aceptan sin rechazo ni adulteraciones.

Esta proposición de los filósofos, como bien puede verse, no resulta indiscutible. La existencia y el progreso de las comunidades humanas puede darse sin la necesidad de esto, por medio de la ley que un sabio por sí solo puede establecer, o bien sugerida por el espíritu de solidaridad del grupo, de manera que sea aceptada por sus miembros y les haga seguir el camino que les marca. Los pueblos que poseen un Libro Sagrado y siguen enseñanzas de profetas son pocos en comparación con los paganos que no poseen libro alguno, que son los que constituyen la mayor parte de la población del mundo. $\mathrm{Y}$, a pesar de ello, viven en grupos organizados y tienen normas, $y$, por supuesto, existen. Y así, los encontramos en nuestra época en regiones inhóspitas del norte y del sur, sin que la vida de esas comunidades sea anárquica, a pesar de que no poseen en absoluto el freno de la ley divina. Esto prueba el error de mantener que la profecía es necesaria, y la falta de lógica que ello supone. La ley divina no es más que un signo de madurez de los pueblos, según la doctrina de los antepasados de nuestra comunidad. Dios es quien concede el éxito y marca el camino (p. 72). ${ }^{23}$

Como decimos, sólo mucho después algunos pensadores «adelantados» a su tiempo no aceptaron el antagonismo dominante entre la razón y los dogmas de la Iglesia. Para ésta, la verdad y la certeza sólo se podía encontrar en la revelación; en opinión de

${ }^{23}$ Capítulo primero, Preliminar I. 
Rougier (1925) citado en Mises (1957: 94), «el problema central de la filosofía escolástica fue demostrar que la razón humana, sin la ayuda de la revelación y las sagradas escrituras, dejada a sus métodos propios de raciocinio, es capaz de probar la necesaria verdad de los dogmas revelados». Por su lado, el pensamiento y el racionalismo moderado de Ibn Jaldún es sorprendentemente moderno, al mismo tiempo, contrario a un determinismo histórico, pero que cree que la evolución de la historia y la cultura tiene unas causas objetivas independientes de la voluntad, del conocimiento y de la conciencia de los hombres, pareciendo una antesala de la crítica al «racionalismo constructivista» de origen cartesiano que Hayek (1959: 90) se preocuparía en denunciar, en lucha frente a las posturas del racionalismo exagerado carentes de una teoría evolutiva de las instituciones:

Mientras la tradición racionalista presupone que el hombre originariamente estaba dotado de atributos morales e intelectuales que le facilitaban la transformación deliberada de la civilización, la evolucionista aclara que la civilización fue el resultado acumulativo costosamente logrado tras ensayos y errores; que la civilización fue la suma de experiencias, en parte transmitidas de generación en generación, como conocimiento explícito, pero en gran medida incorporada a instrumentos e instituciones que habían probado su superioridad. Instituciones cuya significación podríamos descubrir mediante el análisis, pero que igualmente sirven a los fines humanos sin que la humanidad los comprenda.

Antes de que Hayek intuyera la Teoría Evolutiva de las Instituciones de la Escuela Austriaca ya Mises (1932) recoge una idea seminal en el siguiente fragmento citado por Martínez Meseguer (2006: 79-80):

... Hablamos de selección natural de lucha por la vida y de la transmisión hereditaria de las cualidades adquiridas, sin avanzar un sólo paso más que los teólogos o los racionalistas hacia los enigmas supremos. Podemos explicar de este modo el nacimiento y desarrollo de las instituciones sociales, y diremos que favorecen la lucha por la vida; y quienes las han adoptado y perfeccionado están más capacitados para superar los peligros de la existencia 
que aquellos cuyas instituciones sociales han tenido poco desarrollo (...) no era necesario mucho ingenio, en verdad para demostrar que el derecho y el Estado no procedían de contratos.

En definitiva, hemos hallado un texto en el que Ibn Jadún reflexiona y refuta la ley y el gobierno por mandato divino descubriendo el concepto de órdenes espontáneos, resultados de procesos evolutivos que conforman el objeto de estudio de la Teoría Evolutiva de las Instituciones, que diferencia las organizaciones de los órdenes espontáneos. Consecuentemente, y aún siendo un verdadero creyente, podemos confirmar que Ibn Jaldún define una visión laica y racional del orden político refutando la necesidad religiosa. Como diría Mises (1957: 94) «no existe un verdadero conflicto entre la razón y la fe. La ley divina y la ley natural no están en desacuerdo». Abordemos la particular visión del asunto en Mises (1949:187) cuando en el epígrafe «Liberalismo y Religión» de su tratado La acción humana lo define de la siguiente manera:

El liberalismo se asienta sobre una teoría de la cooperación social puramente racional y científica. Las medidas que recomienda son la aplicación de un conjunto de conocimientos que nada tienen que ver con sentimientos, con credos intuitivos sin respaldo lógico, con experiencias místicas ni con personales percepciones de fenómenos sobrenaturales. En este sentido podemos calificar al liberalismo de indiferente o agnóstico, epítetos éstos que pocos utilizan e interpretan correctamente. Pero sería un grave error inferir de ello que las ciencias de la acción humana y la técnica política derivada de sus enseñanzas, el liberalismo, sean ateas u hostiles a la religión. Los liberales rechazan resueltamente todo sistema teocrático pero nada tienen que oponer a las creencias religiosas mientras éstas no interfieran en los asuntos sociales, políticos y económicos.

Por todo ello podemos interpretar que cuando Ibn Jaldún habla de ley religiosa, en cierto sentido se refiere a la ley natural tal y como la entiende el liberalismo. Vemos que en M.N. Rothbard, en su Historia del pensamiento económico I, en su estudio sobre los escolásticos, ambos conceptos son iguales. 
Además, el pensamiento de Jaldún reafirma nuestra tesis sobre su austroliberalismo, a la hora de describir y definir la metodología de estudio de la historia en relación a como la planteara Carl Menger dentro de la «la polémica sobre los métodos» siguiendo la tradición común de los primeros teóricos del orden social espontáneo ya planteada.

A través de un artículo de Huerta de Soto (2006) sobre el libro El método de las ciencias sociales, de Menger, resumimos que, «el conocimiento de la realidad exige de dos disciplinas igualmente importantes pero que, a pesar de su carácter complementario, son radical y epistemológicamente distintas»: la historia constituida por la «materia» y la teoría que de alguna manera es la «forma»; con lo «que la historia sólo puede interpretarse, ordenarse y hacerse comprensible si se tiene una teoría económica previa» (Huerta de Soto, 2010: 71).

La disciplina de la historia,

que estaría constituida por la «materia» (en su sentido aristotélico) que se concreta en los hechos empíricos de cada acontecimiento histórico, que tienen un carácter siempre contingente a las coordenadas de tiempo y lugar determinadas en que se producen (Huerta de Soto, 2006).

Es lo que quiere decir Ibn Jaldún en el Prefacio de nuestra Muqaddima, al comenzar a describir que:

La historia es una de las disciplinas más extendidas entre las naciones y los pueblos. El hombre común desea conocerla y los reyes y los gobernantes la buscan con ansia. Los incultos pueden entenderla tan bien como las personas instruidas pues de hecho la historia no es, en apariencia, más que la relación de los acontecimientos políticos, de las dinastías y de las circunstancias del pasado presentada con elegancia y realzada por medio de citas. Permite agradar a un público amplio y hacernos una idea de los asuntos humanos. Nos muestra los efectos de los cambios, nos explica cómo tal dinastía llegó a conquistar tan gran extensión de tierra hasta el momento en que se dejó oír la Llamada, ${ }^{24}$ cuando su tiempo pasó (p. 3).

${ }^{24}$ La decisión de Dios de que una determinada dinastía llegue a su fin. 
Continúa Huerta de Soto con la teoría, o lo que Menger sugiere como la «forma»:

(en sentido aristotélico) que recoge la esencia (das Wesen) de los fenómenos económicos. Esta forma teórica se elabora partiendo de la introspección, es decir, de la experiencia íntima o reflexión interior del investigador, (...) un valiosísimo conocimiento de primera mano (que Mises denomina «evidencias axiomáticas») que de manera lógico deductiva, y dando entrada en cada paso a los «supuestos» que se consideren relevantes, permite elaborar toda la teoría económica (Huerta de Soto, 2006).

Y como se difunde y evidencia en el presente trabajo, Jaldún cuenta con una teoría económica previa, con la que explica y matiza su argumentación histórica: los orígenes de los acontecimientos, las pruebas y las causas, son advertidos en las consideraciones económicas y en las estructuras sociales evolutivas y admite lo mismo que Menger para la «forma» de la historia:

Sin embargo, contemplada desde su interior adquiere otro sentido que consiste en meditar, esforzarse por encontrar la verdad, en explicar con precisión la causa y los orígenes de los acontecimientos, y en conocer a fondo el porqué y el cómo de las cosas. La historia tiene pues sus raíces en la [Lógica] ${ }^{25}$ y debe ser considerada como una [ciencia]» ${ }^{26}$ (p. 3).

Por su lado, Mises en Teoría e historia, profundiza en cómo debe ser entendida e interpretada correctamente la historia: «el objeto de la historia es poner de manifiesto con toda claridad los factores que han influido en la producción de un acontecimiento determinado» (Mises, 1957: 134):

La historia estudia la acción humana, es decir, las acciones ejecutadas por individuos y por grupos de individuos. Describe las condiciones bajo las cuales las personas vivieron y la manera en

\footnotetext{
25 «Filosofía» que debe ser entendida como Lógica, según nota del traductor.

26 Traducida aquí por «una de sus ramas», se traduce en otros textos por «una ciencia».
} 
que reaccionaron a esas condiciones. Su tema son los juicios de valor y las finalidades que los hombres han perseguido guiados por esos juicios de valor, los medios a los cuales han recurrido para alcanzar las finalidades perseguidas y el resultado de sus acciones. La historia estudia las reacciones conscientes del hombre a las condiciones de su medio, tanto natural como social, determinado por las acciones de generaciones anteriores así como por las acciones de sus contemporáneos (Mises, 1957: 191).

Y volviendo a las palabras de Mises seguidamente matiza una crítica análoga a la que veremos y compararemos con posterioridad:

La filosofía de la historia concibe la historia de la humanidad en una perspectiva diferente. Da por sentado que Dios o la naturaleza o alguna otra entidad sobrehumana dirige providencialmente el curso de los acontecimientos hacia una meta específica diferente de las metas que los hombres en acción tratan de alcanzar...

No tiene sentido argumentar contra doctrinas derivadas de la intuición. Todos los sistemas de filosofía de la historia son intuiciones arbitrarias que no pueden ser ni probadas ni refutadas. No hay medios racionales para apoyar o rechazar una doctrina sugerida por una voz interna (Mises, 1957: 193 y 196).

Ibn Jaldún en su al-Muqaddima, tras el «Prefacio» y en su «Introducción», narra la excelencia de la ciencia histórica, la investigación de sus escuelas, la elucidación de los errores y equivocaciones en que incurren los historiadores, y algunas causas de todo ello, así:

Hay que saber que la historia es una ciencia con varias escuelas, muchas utilidades y noble en sus fines. Nos permite conocer las características de los antiguos pueblos tal y como han quedado plasmadas en su idiosincrasia; a los profetas por sus biografías; a los reyes a través de sus reinos y políticas; y ofrece útiles ejemplos a imitar a quienes los busquen en los acontecimientos religiosos o civiles. Requiere fuentes numerosas y conocimientos variados, así como perspicacia y comprobación de los datos, elementos ambos que conducen a la verdad a quien los ejercita y le apartan de tropiezos 
y errores. Porque las noticias, si se toman sin más en la forma en que son transmitidas, sin examinarlas a la luz de los principios de la razón empírica, de los fundamentos de la politica, de la naturaleza de la civilización y de las características de la sociedad humana; y no se compara lo que no puede contemplarse con lo que sí está a la vista, y lo actual con lo pasado, es muy posible que no se dejen de cometer errores y haya tropiezos y desvíos en el camino de la verdad.

Ocurre con frecuencia a los historiadores, exégetas y grandes cronistas cometer errores en las historias y sucesos porque se basan sin más en lo que les llega, en bruto o depurado, sin someterlo al examen de la razón ni compararlo con otros acontecimientos semejantes. No lo contrastan con la piedra de toque de la filosofía, ni atienden a la naturaleza de los hechos, ni aplican el discernimiento para intentar penetrar y comprender los hechos históricos de manera que se apartan de la verdad y andan perdidos por los desiertos de la fantasía y del error... (pp. 12-13).

Las similitudes expuestas del método de estudio de la historia y la concepción evolutiva de las instituciones entre Ibn Jaldún y La Escuela Austriaca se pueden ampliar incluyendo el campo de la praxeología que merece un análisis más específico que rebasaría el ámbito el presente estudio.

\section{IV}

\section{IBN JALDÚN, RAÍCES DEL LIBERALISMO ECONÓMICO}

Se podría titular «Ibn Jaldún, raíces españolas...» a este ensayo, pues las aportaciones económicas de Ibn Jaldún anuncian la grandiosa contribución de los sabios escolásticos españoles del Siglo de Oro y en cierta medida fortalece los orígenes intelectuales del liberalismo en España, por cuanto Jaldún es de origen español. Así argumenta Francisco Ruiz Girela en el magnífico estudio introductorio a la Introducción a la historia universal (al-Muqaddima) citando al prestigioso especialista Franz Rosenthal: «aunque [Jaldún] siempre profesó un sincero afecto a su tierra natal africana, su verdadera patria intelectual fue España» (p. xix). Continúa Ruiz: 
Además, el afecto que sentía Ibn Jaldún por al-Andalus, debido a que consideraba a esa tierra como el verdadero solar patrio de su familia, se fue incrementando por el hecho de que muchos de sus profesores, y entre ellos los que, según sus propias palabras, más influyeron en su formación, eran de origen andalusí (p. xiv).

Y Rosenthal por su parte:

La Muqaddima menciona con frecuencia la gran contribución que los refugiados andalusíes hicieron a la vida cultural del África nordoccidental y destaca la superioridad de España y la originalidad de su civilización. Esto pone de manifiesto que Ibn Jaldún, más de un siglo después de que su familia hubiese abandonado España, todavía se sentía, en cierta medida, como un miembro de esa gloriosa civilización (p. xix).

Este estudio puede ser la antesala de una posterior investigación para revelar la incógnita sobre posibles influencias intelectuales o vínculos de Jaldún y otros economistas islámicos sobre los escolásticos españoles y el posterior desarrollo de La Escuela Austriaca de Economía; y ello sin perder un ápice de su origen español por no ser una mera coincidencia sino fruto de las relaciones culturales, económicas e históricas entre las tres religiones en al-Andalus. ${ }^{27}$

A continuación ampliamos otros aspectos liberales en la obra de Jaldún que se suman a los ya analizados en el epígrafe III sobre los principios teóricos económicos jaldunianos de La Escuela Austriaca de Economía anteriores a los escolásticos, que en nuestra humilde y sincera opinión consagrarán algún día a este sabio andalusí como una digna autoridad dentro de los padres del liberalismo.

27 En otros campos como el de la literatura religiosa, se ha avanzado en este aspecto demostrando otras influencias islámicas sobre el cristianismo, por ejemplo, en las figuras de los místicos Ibn Arabi, San Juan de la Cruz o Santa Teresa de Jesús. También, véanse las publicaciones del Padre Miguel Asín Palacios, en especial su obra Dante y el Islám (Shamsuddín, 2006). En el campo de la filosofía la transmisión está muy bien documentada. El aristotelismo se introduce en Occidente con Ibn Rushd (Averroes) y muy pronto éste se traduce al latín y el averroísmo se enseña en la Universidad de París y se extiende al resto de universidades europeas elaborándose como el escolasticismo medieval dominante entre los siglos XIII y XV, y es la base en la que Santo Tomás de Aquino escribe la Suma Teológica. 


\section{Cooperación, especialización y división del trabajo}

Jaldún presenta las ventajas y beneficios de la especialización o división del trabajo como una condición necesaria para la supervivencia. Detalla las habilidades necesarias en labores como la agricultura, la artesanía y la fabricación de herramientas indispensables para la obtención de alimentos. Todo desde una perspectiva económica y con ejemplos de las distintas especialidades laborales de su época, cuando trata «de que la organización es algo indispensable para el hombre» (Preliminar I, p. 68 y ss.):

Eso es lo que quieren decir los sabios cuando afirman «que el hombre es social por naturaleza», es decir que no puede vivir sino en sociedad o, lo que es lo mismo, en la ciudad, según el término que utilizan. Éste es el sentido de la civilización, que se explica en el hecho de que Dios —alabado sea-creó al hombre y lo conformó de manera tal que solo puede vivir y mantenerse por medio del alimento, y le dio la tendencia instintiva para buscarlo y la capacidad para conseguirlo. Pero ocurre que la capacidad de un solo individuo del género humano no basta para satisfacer sus necesidades de alimentación, de manera que no lograría, por sí mismo, la cantidad necesaria para vivir.

Destaca que los recursos naturales deben transformarse mediante el trabajo humano y que el trabajo debe pasar por todas las etapas del proceso de producción, en crucial consonancia con la teoría austriaca del capital según la cual la producción lleva tiempo (Menger, 1871: 120) y pasa varias etapas, cada una con su tiempo, y por lo tanto los factores básicos de producción son la tierra, el trabajo y el tiempo. En opinión de O'Driscoll y Rizzo (1996: 43) al verse todos los individuos afectados de forma similar, las decisiones de actuación de un individuo dependen de lo que hagan otros $\mathrm{y}$, esta idea de tiempo, tiene implicaciones en la toma de decisiones que se toman en tiempo real, $\mathrm{y}$ «que el reconocimiento de este hecho por los individuos está en el origen de un comportamiento que sigue reglas y, a un nivel social, del desarrollo de instituciones», que hemos valorado en otro capítulo. Expresándolo en palabras de Jaldún: 
Aún si pensamos en la menor cantidad posible que fuera necesaria, por ejemplo de trigo, no podría tomarlo más que con la manipulación previa necesaria para molerlo, amasarlo y cocerlo, y cada una de estas tres operaciones requiere ayuda de instrumentos que no pueden fabricarse más que con las varias habilidades del herrero, carpintero y el alfarero. Pero admitamos que come el grano sin preparación ninguna: aún así necesitaría para obtenerlo la ayuda de otras muchas faenas como son la siembra, la siega y la trilla, para separar el grano de la cobertura de la espiga, y cada una de estas tres operaciones requiere varios instrumentos y numerosas habilidades, muchas más que las mencionadas antes.

Adelantándose a la división del trabajo de Adam Smith a la que compararemos sorprendentemente por su parecido al exponer más adelante un fragmento del escocés, prosigue Jaldún siempre en su Preliminar I, libro 1:

$Y$ es imposible que para esto, o solo para parte de ello, basten las fuerzas de un solo hombre, sino que necesariamente requiere la asociación de muchas capacidades de los que se dedican a los respectivos oficios, para que tanto su alimento como el de los demás pueda ser obtenido (...) Tiene que contar para ello con la ayuda de los miembros de su especie y, si no cuenta con tal ayuda, no podrá obtener alimentos ni víveres ni podría, por tanto, mantenerse vivo, ya que Dios - ensalzado sea- ha conformado al hombre de manera que necesita alimentarse para vivir. Y tampoco podría defenderse por sí solo si no dispusiera de armas: sería presa de los animales y con ello su muerte sobrevendría, prematuramente, antes de su término natural, lo que haría que la especie humana se extinguiera, mientras que, cuando la colaboración existe, puede obtener alimentos y víveres y armas para defenderse. La sabiduría divina ha decretado su permanencia y la supervivencia de la especie, y por eso la mutua cooperación es indispensable para el género humano pues, sin ella, ni su existencia podría mantenerse, ni se cumpliría el deseo de Dios de habitar el mundo con hombres y hacer que vivan en él como representantes suyos. Este es el sentido de la civilización, que es el objeto de esta ciencia de la que nos estamos ocupando (...) (p. 70).

Vemos que estos conceptos, demostrados de forma similar e inherente en todo el pensamiento jalduniano, se repiten a lo largo 
de la historia especialmente con la denominada por Mises ley de asociación de Ricardo - o teoría de los costes comparativos-que básicamente es una teoría que trata de los principios fundamentales de la cooperación humana bajo la división del trabajo y la especialización e integración de grupos vocacionales, acerca del origen y posterior intensificación de lazos sociales entre los hombres y que es indispensable para entender el origen de la civilización y el curso de la historia (Mises, 1957: 80).

La conclusión de la ley de asociación de Ricardo, mantiene Mises, «simplemente demuestra que la protección no es un medio para lograr el aumento de los bienes producidos» (p. 80) como de forma adyacente deduce y exhorta Jaldún en otro fragmento (4: 12) en el que afirma que todas las protecciones o «todas las regulaciones e inspecciones suponen siempre gastos, y que estos gastos son siempre un impuesto sobre la mercancía y, como consecuencia, sobrecargan al consumidor interior y desaniman al comprador extranjero» (p. 659); y, en consecuencia todos (no sólo unos pocos privilegiados) deberían de observar «la práctica del comercio sin pagar impuestos ni aranceles, pues ésta es la manera más eficaz de incrementar la riqueza y la forma más rápida de obtener beneficios» (3: 38, p. 497). A su vez podemos consultar igualmente en Mises (1949, pp. 189-197) que la «Ley de la División del Trabajo» $\mathrm{y}$ «su corolario, la cooperación humana, es el fenómeno social fundamental» $y$, a la luz de la misma, su correcta explicación sobre la «Ley de Asociación» de Ricardo, ya teorizada y anticipada por el andalusí.

Postura Jalduniana expresada en idénticos términos a la de Mises en relación a la división del trabajo:

La causa de esto es que, como es bien sabido, y ha quedado establecido, un solo ser humano es incapaz de obtener lo que necesita para vivir. Tienen por tanto que colaborar todos en ello para mantener al conjunto de la población, porque ocurre que lo que un grupo de ellos obtiene colaborando obtiene a satisfacer las necesidades de un grupo varias veces más numeroso que ellos mismos.... (4: 11, p. 652).

... el principio de la división del trabajo, posee la ventaja de generar una productividad mayor. Cuando los hombres, coordinadamente, laboran conforme a tal principio (permaneciendo igual todo lo demás) obtienen un producto, no igual a la suma 
de los diversos esfuerzos autosuficientes, sino considerablemente superior (Mises, 1927: 35).

Confirmando lo que analizaremos más adelante: que el aumento o crecimiento de la riqueza es más que proporcional al correlativo aumento de la población; siempre organizada en la división del trabajo.

Gustave de Molinari (1819-1912) argumentaba que para saber cuál es la función del gobierno debemos primero ver la esencia y el objeto de la sociedad misma: «¿A qué impulso natural obedecen los hombres cuando se reúnen en sociedad? (...) ¿Cuál es la razón de ser de este instinto?». Contemplemos las originales explicaciones del libertario francés, a tales preguntas:

Obedecen al impulso o, para ser más exactos, al instinto de la sociabilidad. La raza humana es esencialmente sociable. Los hombres son inducidos por el instinto de vivir en sociedad (...)

El hombre experimenta una multitud de necesidades, de cuyas satisfacciones dependen sus goces y de cuyas insatisfacciones se derivan sus sufrimientos. Ahora bien, encontrándose solo o aislado, el hombre únicamente puede proveerse de esas necesidades, que le atormentan sin cesar, de un modo incompleto e insuficiente. El instinto de la sociabilidad le acerca a sus semejantes y le empuja a ponerse en comunicación con ellos. Entonces, los individuos se aproximan impelidos por el propio interés, estableciéndose cierta división del trabajo necesariamente seguida por intercambios; en breve, vemos surgir una organización mediante la cual el hombre puede satisfacer sus necesidades de forma mucho más completa de lo que podría viviendo aislado (Molinari, 1849).

En otras palabras y en esencia es lo que razona Jaldún cuando argumenta que «la organización social es algo indispensable para el hombre» como acabamos de analizar (1: Preliminar I, pp. 68-72) y llegando a la conclusión de que «La fuerza necesaria para poder satisfacer las carencias de muchos se alcanza, multiplicada, con la colaboración» (p. 69). Vemos esta argumentación conforme a Lamarck (1809) que «no sólo presentó su teoría cincuenta años antes que Darwin, sino que también ofreció una teoría mucho menos violenta sobre los mecanismos evolutivos. La teoría de Lamarck 
sugiere que la evolución se basa en una interacción cooperativa e "instructiva" entre los organismos y el entorno que permite a los seres vivos sobrevivir y evolucionar en un mundo dinámico» (Lipton, 2005: 29). En línea con la concepción anterior leemos:

Sólo el hombre, gracias a la razón, reemplazó la competencia biológica por la cooperación social. Lo que hizo posible la cooperación social es, desde luego, un fenómeno natural, la mayor productividad del trabajo que se logra bajo el principio de la división del trabajo y la especialización de tareas. Pero fue necesario descubrir este principio para comprender su influencia en los asuntos humanos y para emplearlo deliberadamente como medio en la lucha por la existencia (Mises, 1957: 88).

Por otro lado, hemos encontrado en internet un interesante artículo titulado «Ibn Khaldun and Adam Smith: Contributions to the Theory of the Division of Labor and Modern Economic Thought» de James R. Bartkus y M. Kabir Hassan de las Universidades de Louisiana y Nueva Orleans respectivamente, que transcribe los sorprendentes parecidos entre Ibn Jaldún y Adam Smith en esta materia. En el capítulo uno del que se considera el primer libro moderno de economía, Smith constataba los beneficios de la división del trabajo con su famoso ejemplo de la fábrica de alfileres, pero cuatro siglos después de que lo hiciera Jaldún y coincidiendo también con él hasta en el número de capítulo de su Muqaddima. Contemplemos las similitudes cuando el "padre de la economía descubre» las bondades de la división del trabajo, el beneficio para la sociedad de la especialización y la cooperación en la producción:

Un trabajador no preparado para esta actividad (que la división del trabajo ha convertido en un quehacer específico), no familiarizado con el uso de la maquinaria empleada en ella (cuya invención probablemente derive de la misma división del trabajo), podrá quizás con su máximo esfuerzo, hacer un alfiler en un día, aunque ciertamente no podrá hacer veinte. Pero en la forma en que esta actividad es llevada a cabo actualmente no es sólo un oficio particular sino que ha sido dividido en un número de ramas, cada una de las cuales es por sí misma un oficio particular. Un 
hombre estira el alambre, otro lo endereza, un tercero lo corta, un cuarto lo afila, un quinto lo lima en un extremo para colocar la cabeza; el hacer la cabeza requiere dos o tres operaciones distintas; el colocarla es una tarea especial y otra el esmaltar los alfileres; hasta el empaquetarlos es por sí mismo un oficio ... Ahora bien, si todos hubieran trabajado independientemente y por separado, y si ninguno hubiese estado entrenado para este trabajo concreto, es imposible que cada uno fuese capaz de fabricar veinte alfileres por día, y quizás no hubiesen podido fabricar ni uno... Smith (1776: 34-35).

\section{El ahorro, el capital y el empresario como fuente de riqueza}

La política antiliberal es una política de consumo de capital (Mises, 1927: 24). La Escuela Austriaca, en contra de la corriente principal de la teoría neoclásica, basa el fundamento de la prosperidad en el ahorro y la acumulación de capital. La particular explicación jalduniana es que la riqueza se acumula por la producción no consumida y ahorrada, y esos ahorros se acumulan en forma de dinero y después se invierten en diversos géneros de bienes de capital. Al respecto, es de apreciar la parte del siguiente pasaje que destacamos, en el que «trata de cómo los países, en sus diferencias de situación en cuanto a riqueza y pobreza, son semejantes a las ciudades» (4:14):

Debe tenerse en cuenta que, mientras que la población y el grado de actividad social de los países son relevantes, numerosos los pueblos que habitan entre sus límites y muchos sus habitantes, las condiciones de vida de sus gentes son holgadas, grandes sus riquezas y sus ciudades, y poderosas sus dinastías y sus reinos. La razón de todo esto es lo que ya antes dijimos sobre la abundancia de trabajos y lo que más adelante diremos sobre las causas de la riqueza: que el excedente del que se dispone, tras atender las necesidades vitales y a las exigencias de los habitantes — tanto cuanto mayores son la población y su grado de actividad social-, revierte en la gente como beneficio susceptible de acumularse como patrimonio, tal como mencionaremos en el capítulo que tratará de los medios de vida y del sentido de «sustento» $\mathrm{y}$ de «beneficio» (pp. 661-662). 
Y, tras la división del trabajo, en otro fragmento (5: 16) Jaldún establece que «los oficios sólo alcanzan su perfección cuando la población sedentaria también se ha desarrollado plenamente y es numerosa», en el que confirma idéntica explicación resaltando el mismo efecto positivo del ahorro:

La causa de esto es que, mientras la población sedentaria no ha alcanzado su pleno desarrollo y la ciudad no está bien estableci$\mathrm{da}$, la gente solo se preocupa de las necesidades primarias de su vida, las que resultan indispensables para ella, consistentes en obtener el alimento a partir del trigo y otros productos. Pero cuando la sociedad se ha desarrollado y han aumentado en ella los trabajos, éstos resultan ya suficientes para atender las necesidades primordiales y aún producen algo más. Y ese exceso se emplea en elementos de comodidad para la vida... (p. 726).

Benegas Lynch suele usar como ejemplo que los salarios son más altos en Vancouer que en Bombay, no gracias a la presión de los sindicatos sino a sus diferentes tasas de capitalización. Es decir, en un país es más productiva la hora de trabajo en cualquier persona cuanto mayores sean las inversiones o su industrialización, esto es, conforme sea más capitalista. Benegas (1972) lo expresa así:

«(...) Allí donde el stock de capital es mayor en relación con el trabajo, los salarios serán más elevados. Estos salarios no son más elevados porque el trabajador realiza mayor esfuerzo, por el contrario, el esfuerzo será menor Y, eventualmente, las jornadas más cortas, pero la productividad es superior debido a que los equipos de capital potencian la energía humana, lo cual permite los mayores rendimientos» (p. 320).

Por su parte Mises (1949) señala que «(...) lo malo de Asia comparado con Europa es que, en comparación con Europa, hay allí muy poco capital por individuo» (p. 988). Similitudes en los motivos de estas diferencias de riqueza entre países las encontramos en Jaldún (4: 17) —al indicar las causas de la solidez de una dinastía que hacen que la civilización se asiente firmemente- concorde a la mayor o menor productividad de sus oficios debido a una mayor o menor especialización y dominio en la población. Luego, 
personifica el desarrollo tecnológico en el capital humano especializado que ayuda al crecimiento económico:

La causa de esto es que la civilización consiste en determinados hábitos que van más allá de aquellos que son indispensables para que exista vida social, en una medida que depende de las diferencias de prosperidad y del mayor o menor tamaño de las diversas naciones. Tales diferencias pueden ser muy grandes y resultan proporcionadas a la diversificación de clases y gremios, de la misma manera que ocurre con los oficios. Cada uno de los gremios requiere de personas que lo integren y lo ejerzan con maestría. Y en la medida que haya más especialidades, mayor será el número de personas dedicadas a ese oficio. Y quienes en él se ocupan van adquiriendo una especial idiosincrasia. Con el paso del tiempo esos oficios se van perpetuando y los artesanos que a ellos se dedican van adquiriendo destreza y maestría en su conocimiento. Lo dilatado de las edades y la amplitud de los periodos, así como la repetición de los modelos, consolida su estabilidad y su firmeza. Y esto es algo que ocurre predominantemente en las ciudades debido al mayor desarrollo de su población a la mayor prosperidad de sus habitantes (...) Así, la riqueza de éstos aumenta, se incrementa su capital, y prospera todo aquello en lo que se basa el lujo y constituye sus manifestaciones ... (p. 668).

Concorde al liberalismo económico observamos en Jaldún el dicho de que la diferencia entre una sociedad rica y una pobre radica esencialmente en que la rica tiene muchos más bienes de capital invertidos o más especialización y dominio en los oficios que una sociedad pobre; y ello es más fácil cuanto mayor sea su población, como abordaremos en epígrafe aparte.

A lo largo de la Muqaddima se denuncia que una de las mayores injusticias, si no la mayor y más perjudicial para la civilización y para la dinastía, consiste en apoderarse por parte del gobierno de la riqueza de la gente ${ }^{28}$ comprándoles lo que tienen a un precio muy bajo y luego imponiéndoles la compra de los productos a un precio muy alto por medio de la coerción y forzándoles así

28 Véase el epígrafe 4 II «El efecto destructor del comercio ejercido por el Estado» del presente ensayo. 
a vender y a comprar: «Las pérdidas afectan a todas las clases y profesiones, se hacen más graves conforme pasa el tiempo, hasta que acaban consumiendo el capital».

«El capitalismo es fundamentalmente producción en masa para satisfacer las necesidades en masa» (Mises, 1957: 156); y también Jaldún parece aventurar una concepción o una noción de un sistema igual al capitalismo en el que "prospera todo aquello en lo que se basa el lujo» y que según sus palabras consolida, da firmeza y prosperidad a la sociedad; y que no empobrece a los trabajadores sino que mejora su nivel de vida, preconizando un sistema con expresiones como «la repetición de modelos», «desarrollo» $y$ riqueza que «incrementa el capital».

En el mismo sentido, Jaldún concibe al empresario como fuente de riqueza, es decir, el concepto de mercader tiene un eje clave, una importancia que centra en su función empresarial y que entiende ahora como el «empresario-capitalista» que en sus exposiciones es la fuerza motriz de la economía de mercado y el protagonista de muchos argumentos jaldunianos: debe acumular primero capital ahorrado en orden a adelantar los factores de producción, y al mismo tiempo que elabora el producto y asume los riesgos de la incertidumbre del mercado sufre las injusticias intervencionistas. Cuando Jaldún «trata de las diferentes formas de ganarse la vida, sus clases y procedimientos», advertimos plasmada la definición de empresario o comerciante (5:2) como una forma natural de obtener ganancia, consistente en «argucias para hacerse con el margen existente entre los precios de compra y de venta, para obtener la ganancia que supone esta diferencia. Por eso la ley religiosa permite la astucia en él, porque el comercio tiene algo de juego de azar...» (p. 695). Ideas revividas y defendidas por los escolásticos salmantinos y, varios siglos después, en otras partes de Europa por los calvinistas, con máximas como: «triunfar en un negocio es un deber religioso», o «el beneficio es un don del cielo», o «enriquecerse es un medio de loar a Dios y de servirle»; expresiones recogidas por Goitein (1957), citado en Lacoste (1965: 261).

Incide de nuevo Jaldún en la idea de que el empresario representa la fuente de riqueza - además de cuando ataca a los propios impuestos que tienen que pagar y a la coacción estatal-, en el fragmento del pasaje (3:38) donde alude a que [la riqueza del sultán], 
y el crecimiento de ésta sólo se logra con un trato justo hacia aquellos que poseen riqueza y mirando por ellos, pues eso hace que sus expectativas se amplien y que sus espiritus se animen a obtener los frutos de la riqueza y a hacerla prosperar, con lo que aumenta la recaudación del sultán - [y que interferencias del tal sultán] como dedicarse al comercio o a la agricultura - no hace más que provocar un daño rápido a los súbditos, una pérdida de la recaudación y un decaimiento de la actividad productiva (497).

El argumento anterior de que el crecimiento o la riqueza se crea «mirando por las personas que tienen dinero» - en consonancia con su ahorro susceptible de inversiones productivas-es por su propia naturaleza contrario a la idea de la distribución de la riqueza, de la cual consecuentemente Jaldún no hace mención alguna; entiende que existiendo desigualdad y distribución no igualitaria se genera riqueza. Es decir, el incentivo personal de la mejora individual se asocia causalmente con la creación de riqueza, «dando trato justo a aquellos que poseen riqueza y mirando por ellos, pues eso hace que sus expectativas se amplíen y que sus espíritus se animen a obtener los frutos de la riqueza y a hacerla prosperar» ${ }^{29}$ : además de la función empresarial o la defensa de la naturaleza innata de todo ser humano a emprender, resuelve que lo que es rentable para el individuo también lo es para la sociedad, contrariando la que es la principal argumentación de la literatura anticapitalista según Mises (1927: 22-25 y 85-86).

Vemos también desarrollada dicha idea en Mises, y en plena vigencia, pues el capitalismo intenta producir lo que puede al costo más bajo posible, «lo cual permite atender, cada vez mejor, las necesidades de las masas consumidoras»,

y tales logros son precisamente consecuencia de la desigualdad de rentas y patrimonios, pues esa disimilitud es el motor que a todos, ricos y pobres, induce a producir lo máximo que en su mano esté... Suprimidos los aludidos estímulos, reduciríase inevitablemente la riqueza total, de modo que, efectuada la tal ansiada redistribución igualitaria, serían aún más míseras esas personas a las que, en la actualidad, denominamos pobres (Mises, 1927: 50).

${ }^{29}$ Y esto propicia que el estado o sultán recaude más, también visto en otros epígrafes y entre otros pasajes como, por ejemplo, en el que comentamos su anticipación del efecto o curva de Laffer. 
Reiteramos, son ideas todas ellas en consonancia con la propiedad privada y el incentivo personal innato en cada persona como parte de su naturaleza emprendedora o función empresarial, cimiento de la prosperidad económica.

\section{Población y prosperidad}

La división del trabajo da paso a atender otras necesidades, como la seguridad, y alcanza su perfección cuando la población sedentaria también se ha desarrollado plenamente y es numerosa. Son abundantes las citas en la Muqaddima en las que Ibn Jaldún analiza, explica y hace referencia, a que la causa de la riqueza de los países es proporcional al aumento de las poblaciones que implica más trabajos disponibles; en sus palabras «la rivalidad de las ciudades y grandes poblaciones en cuanto a mayores comodidades y mayor actividad económica, dependen sólo de que su población sea mayor o menor». Hemos señalado ya este aspecto al comentar los precios de los salarios y de los bienes de lujo, que Jaldún menciona son posibles mientras la población y la consecuente oferta de trabajo aumente y haya también demanda de los mismos. Por contra, en el desierto y mientras su población sea nómada y escasa, y no se consolide el comercio, sólo tienen necesidad de cubrir lo básico para vivir y no se da lugar a la correspondiente especialización ni a la generación de la riqueza.

Consideremos ahora la idea de dos de los principales pensadores de la Escuela Austriaca de Economía acerca de las bondades del aumento de la población:

El principal límite al desarrollo de la civilización es una población estancada, pues imposibilita continuar el proceso de profundización y especialización del conocimiento práctico que es necesario para el desarrollo económico (Huerta de Soto, 2005, p. 82).

Igualmente en Hayek la ficción de que el aumento demográfico haría la vida más miserable, es refutada al afirmar que «nos hemos convertido en civilizados por el incremento de nuestro número, así como la civilización ha hecho ese incremento posible: podemos ser 
pocos y salvajes, o muchos y civilizados» (Hayek, 1988: 360), e idéntica también, a la versión jalduniana «que trata de cómo la civilización en las ciudades es consecuencia del establecimiento de las dinastías, y de cómo es la continuidad y solidez de la dinastía lo que hace que la civilización se asiente firmemente» (4:17, p. 667). La situación de la dinastía se manifestará en el bienestar de los súbditos, de manera que cuanto mayor sea el bienestar de los súbditos y éstos más numerosos, así será la riqueza de la dinastía. Luego la raíz de todo es el número de habitantes que realiza su meta en su grado de desarrollo y organización social (4:18, p. 672).

$\mathrm{Y}$, en caso contrario, reafirmando esta postura, leemos en el siguiente pasaje (5:1):

(...) Debe tenerse en cuenta que cuando los trabajos desaparecen o escasean por causa del descenso de la población, Dios permite que la posibilidad de obtener ganancia también desaparezca. Así puede verse en las ciudades con escaso número de habitantes cómo escasean en ellas el sustento y la ganancia, o no se encuentran en absoluto, debido a la escasez de trabajos humanos.

Consecuentemente, en las ciudades en las que la población es mayor, su población vive en condiciones más holgadas y con más lujos, como antes dijimos. Por eso es por lo que el vulgo dice que en las ciudades en las que la población ha disminuido ha desaparecido el sustento. Así ocurre inclusive con las fuentes y los cursos de agua: que dejan de manar y fluir en las zonas secas. Porque los manantiales de las fuentes sólo existen cuando se cavan y se les hace aflorar, y eso exige trabajo humano. Y lo mismo ocurre con el ordeño de los animales. Porque si no se hace aflorar los manantiales y no se les draga, el agua se filtra y se pierde toda, igual que se secan las ubres si no se ordeñan. Obsérvese cómo en las ciudades en las que se sabe que había fuentes en la época en la que su población era abundante, ocurre que, cuando les sobrevino la ruina, el agua que de ellas salía desapareció completamente como si jamás la hubiera habido. Dios determina la noche y el día (p. 693).

Y, en gran número de pasajes, Jaldún hace referencia a la misma idea, por ejemplo, cuando comenta (5: 19) que «En las ciudades cuando se aproxima su ruina, van desapareciendo los oficios» (p. 731); o (5:17) que «Los oficios solo se encuentran firmemente 
establecidos en las ciudades en las que la cultura urbana también lo está y lo ha estado durante un periodo prolongado» (p. 728). En todos estos epígrafes explica minuciosamente paso a paso cada una de los razonamientos que le llevan a la idea común con el liberalismo, de que el crecimiento de la población favorece la prosperidad que tenemos razonada teóricamente de forma afín por Huerta de Soto, para el cual el aumento continuo de la población no sólo es la condición teórica necesaria para el desarrollo económico sino además es la consecuencia más típica de la evolución social (Huerta de Soto, 1992: 80-85; y 1994: 98).

\section{Mercado y desarrollo social}

A lo largo de todo este artículo vemos una defensa del comercio emparejado a la libertad de la función empresarial, la propiedad y el libre mercado. Específicamente observamos, ahora aquí también, la importancia que otorga Jaldún al mercado en cuanto factor clave para el establecimiento de las dinastías y de su continuidad y solidez, pues la actividad del mercado es lo que hace que la sociedad se asiente estimulando firmemente los oficios establecidos de todas las artes, que es lo que constituye la civilización urbana. Llega a equiparar los términos dinastía, sultán y mercados como sinónimos, pues el desarrollo social o de la dinastía viene aparejado al desarrollo del mercado que es un signo de aquellos:

(...) Esto ocasiona también que en las ciudades alejadas, aunque posean una población abundante, predominen las formas de vida beduinas y se mantengan alejadas de la civilización urbana en todas sus manifestaciones, a diferencia de lo que ocurre en las ciudades centrales, las que están en las comarcas que constituyen la sede de la dinastía o en sus proximidades. Esto es así solo por la cercanía del gobierno a ellas y por el flujo del dinero que reciben, de forma semejante a lo que ocurre con el agua, que hace que verdee la tierra que está próxima, mientras que queda seca la que está alejada. Ya hemos dicho anteriormente que el sultán y la dinastía son como un mercado en el mundo, y que todas las mercancías se hallan en el mercado o en sus proximidades, y que, conforme se aleja uno del mercado, todas estas mercaderías van 
escaseando. Y cuando esta dinastía [o mercado] se prolonga en el tiempo y sus reyes se suceden uno tras otro en esa ciudad, la civilización urbana se va asentando y se enraíza cada vez con mayor firmeza (p. 669).

\section{El trabajo y la fuente originaria de la propiedad}

Hayek (1990: 65-77) en su análisis sobre Los orígenes de la libertad, la propiedad y la justicia, sugiere que «donde no hay propiedad no puede haber justicia». Por su lado, en el origen de la propiedad, el anarcocapitalismo defiende el derecho de cada persona a los frutos de su trabajo; que además es legítima propietaria de los recursos sin propietario previo, sobre los cuales haya realizado alguna forma de trabajo. En Jaldún (5:1) queda clara la idea capitalista de obtención de beneficio, y que el origen de las ganancias en su totalidad o en parte, no es más que el valor del «trabajo» humano - pero en nada se confunde como hemos visto con la teoría del valor-trabajo:

Una vez establecido todo esto es necesario saber, respecto a la riqueza que el hombre gana y obtiene ejerciendo un oficio, que esa ganancia y ese beneficio representa el valor de su trabajo. Y eso es lo que quiere decir con «obtención», (...) Cuando el beneficio se obtiene con algo que no es un oficio artesano, necesariamente en el valor de ese beneficio y esa ganancia tiene que incluirse el valor del trabajo que se ha requerido, puesto que sin trabajo no se obtendría nada. En la mayoría de los casos la participación del trabajo es evidente y representa una parte mayor o menor del valor [que se explica en el capítulo III de este artículo refutando la teoría del valor-trabajo] (...) (p. 692).

En línea a la apropiación, Salin (2000: 74) afirma que «en la medida en que la creación de riqueza se deriva de la aplicación individual de la razón, reconocer la naturaleza humana de alguien implica asumir sus derechos de propiedad sobre lo que sea capaz de crear», de donde resulta imposible separar un bien económico - una riqueza - de su creador. 


\section{CONCLUSIONES}

Hemos expuesto las ideas de una economía política basada en la práctica no-intervencionista en el pensamiento de Ibn Jaldún que utiliza principios económicos de la economía de mercado, así como gran parte de los elementos básicos del liberalismo económico en los que posteriormente se asentaron los maestros austriacos. En este sentido puede incluirse y aceptarse a Jaldún como un autor liberal y precursor de la Escuela Austriaca de Economía. La importancia de sus ideas liberales las hemos elegido, comprendido y comentado en el presente estudio incluyendo pasajes con contenidos económicos hasta ahora olvidados por el ámbito académico económico occidental.

Mostramos el paralelismo entre las tesis de Huerta de Soto sobre la imposibilidad teórica del socialismo con el pensamiento de Ibn Jaldún, centrándonos en la coacción gubernamental que se manifiesta en la agresión contra los derechos naturales como la propiedad privada y la función empresarial - con la consiguiente ausencia de motivación y descoordinación del mercadoque degeneran en la corrupción de los dirigentes, la destrucción de la moral y finalmente de la civilización. Las similitudes entre ambos análisis, demuestran la convicción austro-liberal de este autor que aboga a favor del derecho fundamental de la libertad del ser humano y de su naturaleza innata empresarial.

Descubrimos la originalidad de su pensamiento económico, digno precursor de la teoría económica liberal, anticipándose a los escolásticos españoles con su concepción subjetivista y el resto de principios económicos de vertiente liberal - recordemos la defensa del comercio, de la economía libre y la importancia de la población- en línea con la posterior corriente de pensamiento económico austro-liberal; destacando, además, las ideas centrales de la no-intervención del estado en la economía, con especial incidencia en la condena a los impuestos y a la agresión en contra de la función empresarial. Por su incidencia en la especialización, la cooperación y la división del trabajo, hay quienes lo convierten también en precursor de dichas ideas en Adam Smith. 
Pero Ibn Jaldún va más allá y relaciona e integra toda su visión económica con los ciclos u ocasos de las civilizaciones, con la cohesión social libre y natural, y su buen funcionamiento. Hemos visto en Ibn Jaldún un pensador avanzado a su época desmantelando la teoría divina de las instituciones, aproximadamente tres siglos antes que la Ilustración, gracias a la indagación y al razonamiento, coincidiendo con destacados autores austriacos en la teoría de las instituciones evolutivas y el respeto a la ley religiosa como ley natural.

Este estudio también abre la puerta a otros campos de investigación y aplicación de los pensamientos de Ibn Jaldún, fundamentalmente, su idea de las crisis cíclicas y los motivos de las mismas como precursora de la Teoría Austriaca del Ciclo Económico; las teorías económicas abordadas en su Introducción a la Historia Universal (Prolegómenos o al-Muqaddima), además de adelantadas a su tiempo, tienen plena vigencia dada su sorprendente precisión objetiva y descriptiva de los acontecimientos, y son relevantes no sólo en el ámbito de la historia sino de un mayor estudio crítico y realista de la economía y la crisis actual, al abordar y denunciar cuestiones o injusticias tales como la coacción gubernamental y la violación de los derechos de propiedad, como causantes de la ruina o destrucción de la civilización.

Otro aspecto de la misma investigación que invita a profundizar en el estudio del pensamiento económico, social y político de Ibn Jaldún es, sobre todo, el análisis de la imposibilidad del socialismo. Otros aspectos ampliables en la línea del presente trabajo de análisis de la Muqaddima son las ideas jaldunianas sobre la metodología del estudio de la historia y la praxeología. En definitiva, en «Austro-liberalismo en Ibn Jaldún» hemos reconocido y recuperado a Ibn Jaldún como un autor proto-austriaco, todo lo cual podría dar pie a un distinto estudio sobre las raíces u origen del análisis económico austriaco en suelo español anterior a los escolásticos cristianos.

Pero, inmersos en una crisis de intervencionismo estatal, encontramos de máxima actualidad y utilidad el juicio de este sabio andalusí - sorprendentemente moderno y a la altura del siglo XXI - para, además de adaptar y aplicar su conocimiento a la problemática actual buscando posibles soluciones, al mismo 
tiempo reivindicar su figura como referente común entre las distintas culturas de Oriente y Occidente. Para aquellas sociedades musulmanas Ibn Jaldún y su visión de la economía de mercado puede significar un vínculo de acercamiento que les haga penetrar y concebir al capitalismo de forma totalmente acorde a sus creencias y cultura, plenamente afín con el pensamiento de La Escuela Austriaca de Economía y el austroliberalismo. Como diría Gabriel J. Zanotti (Mises, 1927: 14) sobre el proyecto de Menger y su continuador Mises, el pensamiento jalduniano también es «una economía universal válida para todo lugar y tiempo».

\section{REFERENCIAS BIBLIOGRÁFICAS}

Asad, M. (2001): El Mensaje del Qur an. Traducción del árabe y comentarios. Traducción del inglés al español Abdurrasak Pérez. Junta Islámica. Centro de documentación y publicaciones islámicas.

Asín Palacios, M. (2007): Dante y el Islam. Urgoiti Editores, S.L. BALMES, J. (1925): «Verdadera idea del valor o reflexiones sobre el origen, naturaleza y variedad de los precios», en Obras completas, tomo XI, Barcelona.

BARTKUS, J.R. y KABIR HASSAN, M., «Ibn Khaldun and Adam Smith: Contributions to the Theory of the Division of Labor and Modern Economic Thought», Southeastern Louisiana University y University of New Orleans. Edición digital texto completo en pdf. en http://www.uned.es/congreso-ibnkhaldun/pdf/08\%20Kabir\%20Hassan.pdf.

BENEGAs Lynch, A. (h) (1972): Fundamentos de análisis económico 12.. ed. ampliada, Ediciones Sociedad Abierta, Panamá, 2011.

Chafuen, A. (1991): Raíces cristianas de la economía de libre mercado. El buey mudo, 2009.

FisHer, I. (1930): La teoría del interés. Ediciones Aosta, Madrid 1999.

GÓmEz RIVAS, L.: «Jaime Balmes (1810-1848) y el marginalismo en España». Universidad Europea de Madrid. Documento en línea desde Internet, extraído el 20 de mayo de 2011.

HAYEK, F.A. (1988): La fatal arrogancia: Los errores del socialismo. Unión Editorial, Madrid 1990 
- (1959): Los fundamentos de la libertad. Unión Editorial, Madrid 1998.

Hoppe, H.H., Hülsmann, J.G., y Block, W. (2003): The Myth of National Defense, Ludwig von Mises Institute.

Huerta De Soto, J. (1992): Socialismo, cálculo económico y función empresarial. Unión Editorial, Madrid (4. a ed. 2010).

- (1986): Lecturas de Economía Política I. Unión Editorial, Madrid.

- (1987): Lecturas de Economía Política II. Unión Editorial, Madrid 2008, 2.․ ed.

- (1994): Estudios de Economía Política. Unión Editorial, Madrid.

- (1998): Dinero, crédito bancario y ciclos económicos. Unión Editorial, Madrid 2011, 5. ed. $^{\text {ed }}$

- (2002): Nuevos estudios de Economía Política. Unión Editorial, Madrid.

- (2006): «Huerta de Soto sobre Menger». Libros de Economía y Empresa. Fundación Caja Duero. Real Academia de Ciencias Morales y Políticas: http:/ / www.librosdeeconomiayempresa.es/r004/articulo19.aspx.

- (2010): La Escuela Austriaca: mercado y creatividad empresarial. Edit. Síntesis, Madrid.

Hume, D. (1752): Ensayos políticos. Centro de Estudios Constitucionales, Madrid 1982.

JALDÚN, I. (1379): Introducción a la historia universal (al-Muqaddima). Almuzara, Córdoba 2008.

Lacoste, Y., (1965): El nacimiento del tercer mundo: Ibn Jaldún. Ediciones Península, Barcelona 1971.

Lipton, B.H. (2005): La biología de la creencia. Editorial Palmyra. Traducción Concepción Rodríguez González.

Martínez Meseguer, C.(2006): Teoría evolutiva de las instituciones. Unión Editorial, Madrid.

Menger, C. (1871): Principios de Economía Política. Unión Editorial, Madrid 1997.

Mises, L. V., (1927): Liberalismo. Unión Editorial, Madrid, 1977.

- (1957): Teoría e historia. Unión Editorial, Madrid, 2010.

- (1950): «Lord Keynes and Say's Law». The Freeman. 30 de octubre. Traducción Juan Ramón Rallo Julián. Extraído el 
20 de mayo de 2001 desde http://www.liberalismo.org/ articulo/341/.

- (1949): La acción humana: tratado de economía. Unión Editorial Madrid, (10.르 ed. 2011).

MolinARI, G. (1849): «De la production de la securité», Journal des Économistes, XXV (feb. 1849), pp. 277-90. Traducida como «Sobre la producción de seguridad». Traducción de Gabriel Calzada, Procesos de mercado, vol. III, n. ${ }^{\circ}$ 1, primavera 2006, pp. 219-236.

NASSAR, N. (1967): El pensamiento realista de Ibn Jaldún. Fondo de Cultura Económica. México 1979.

O’Driscoll, G.P. Jr. (1996): La economía del tiempo y la ignorancia. Unión Editorial, Madrid 2009.

Rothbard, M.N. (1995): Historia del pensamiento económico Vol. I, Unión Editorial, Madrid 1999.

SALIN, P. (2000): Liberalismo. Una nueva y profunda evaluación del pensamiento liberal. Unión Editorial, Madrid 2008.

Temin, P. (2009): «La economía del Alto Imperio Romano», Procesos de Mercado, vol. VI, n.․ 2, Otoño.

SHAmsuddín, E.R.H. (2006): Dante y el Islam. Maestro Verde y Editorial Premura, Barcelona.

Sмith, A. (1776): La riqueza de las naciones. Alianza Editorial Madrid 1994.

VADILlo, U.I. (2005): Una crítica islámica de la economía. Edición digital a texto completo accesible en www.eumed.net/libros / 2005/uiv-eco/

VALENCIA, R. (1985): Ibn Jaldún: introducción a la historia. Bibl. de la cultura andaluza. Sevilla. 